\title{
The impact of sevoflurane anesthesia on postoperative renal function: a systematic review and meta-analysis of randomized- controlled trials
}

\section{Impact d'une anesthésie au sévoflurane sur la fonction rénale postopératoire : revue systématique et méta-analyse des études randomisées contrôlées}

\author{
Rakesh V. Sondekoppam, MBBS, MD • Karim H. Narsingani, MSc • Trent A. Schimmel, BSc • \\ Brie M. McConnell, MLIS · Karen Buro, Dr rer nat · Timur J.-P. Özelsel, MD, DESA (1)
}

Received: 21 December 2019/Revised: 5 May 2020/Accepted: 11 May 2020/Published online: 18 August 2020

(c) Canadian Anesthesiologists' Society 2020

\begin{abstract}
Purpose Renal damage secondary to fluoride ions and compound A (CpdA) after sevoflurane anesthesia remains unclear. For safety reasons, some countries still recommend minimum fresh-gas flows (FGFs) with sevoflurane. We review the evidence regarding the intraoperative use of sevoflurane for anesthesia maintenance and postoperative renal function compared with other anesthetic agents used for anesthetic maintenance. Secondarily, we examine the effects of peak
\end{abstract}

Electronic supplementary material The online version of this article (https://doi.org/10.1007/s12630-020-01791-5) contains supplementary material, which is available to authorized users.

R. V. Sondekoppam, MBBS, MD

Department of Anesthesia, University of Iowa Carver College of Medicine, Iowa City, IA, USA

K. H. Narsingani, MSc · T. A. Schimmel, BSc

University of Alberta Medical School, Edmonton, AB, Canada

B. M. McConnell, MLIS

Schulich School of Medicine and Dentistry, Western University, London, ON, Canada

K. Buro, Dr rer nat

Department of Mathematics and Statistics, MacEwan University, Edmonton, AB, Canada

T. J.-P. Özelsel, MD, DESA ( $\square$ )

Department of Anesthesia and Pain Medicine, University of Alberta, 2-150 Clinical Sciences Building (CSB), $8440112 \mathrm{St}$ NW, Edmonton, AB T6G 2G3, Canada

e-mail: ozelsel@ualberta.ca plasma fluoride and CpdA levels and the effect of FGF and duration of anesthesia on these parameters.

Source The databases of MEDLINE (OVID and Pubmed), EMBASE, the Cochrane Library, Health Technology Assessment Database, CINAHL, and Web of Science were searched from inception until 23 April 2020 to identify randomized-controlled trials (RCTs) in humans utilizing sevoflurane or an alternative anesthetic for anesthesia maintenance with subsequent measurements of renal function. Two different paired reviewers independently selected the studies and extracted data. The quality of the evidence was appraised using GRADE recommendations. Principal findings of 3,766 publications screened, 41 RCTs in human patients were identified. There was no difference between creatinine at $24 \mathrm{hr}(21$ studies; $n=$ 1,529), or creatinine clearance (CCR) at $24 \mathrm{hr}$ (12 studies; $n=728)$ in the sevoflurane vs alternative anesthetic groups. Peak fluoride and fluoride measured at $24 \mathrm{hr}$ were higher with sevoflurane compared with other inhaled anesthetics. Subgroup analyses for sevoflurane usage in various contexts showed no significant difference between sevoflurane and alternative anesthetics for creatinine or $C C R$ at $24 \mathrm{hr}$ at varying FGF, duration of exposure, baseline renal function, or absorbent use.

Conclusions We did not find any association between the use of sevoflurane and postoperative renal impairment compared with other agents used for anesthesia maintenance. The scientific basis for recommending higher FGF with the use of sevoflurane needs to be revisited. 


\section{Résumé}

Objectif Les lésions rénales secondaires aux ions fluorure et au composé A (CpdA) après une anesthésie au sévoflurane demeurent incertaines. Pour des raisons de sécurité, certains pays recommandent encore des débits de gaz frais (DGF) minimaux lors de l'utilisation du sévoflurane. Nous avons passé en revue les données probantes concernant l'utilisation peropératoire de sévoflurane pour le maintien de l'anesthésie sur la fonction rénale postopératoire comparativement à d'autres agents anesthésiques utilisés pour le maintien de l'anesthésie. En analyse secondaire, nous avons examiné les effets des taux plasmatiques maximaux de fluorure et de CpdA et l'effet du DGF et de la durée de l'anesthésie sur ces parametres.

Source Des recherches ont été menées dans les bases de données de MEDLINE (OVID et Pubmed), EMBASE, the Cochrane Library, Health Technology Assessment Database, CINAHL et Web of Science, de leur création jusqu'au 23 avril 2020. Nous y avons identifié les études randomisées contrôlées (ERC) réalisées sur des sujets humains utilisant du sévoflurane ou un agent anesthésique alternatif pour le maintien de l'anesthésie et présentant des mesures subséquentes de la fonction rénale. Deux différents réviseurs appariés ont selectionné de manière indépendante les études et extrait les données. La qualité des données probantes a été évaluée à l'aide des recommandations GRADE.

Constatations principales Parmi les 3766 publications passées en revue, 41 ERC réalisées chez des patients humains ont été identifiées. Aucune différence n'a été observée en ce qui touchait à la valeur de créatinine à $24 \mathrm{~h}$ (21 études; $n=1529)$ ou de la clairance de la créatinine (CCR) à $24 h$ (12 études; $n=728)$ dans les groupes sévoflurane vs autres anesthésiques. Les taux maximaux de fluorure et le fluorure mesuré à 24 h étaient plus élevés lors de l'utilisation de sévoflurane que d'autres agents anesthésiques halogénés. Les analyses de sous-groupe portant sur l'utilisation du sévoflurane dans divers contextes n'ont démontré aucune différence significative entre le sévoflurane et les autres anesthésiques en matière de valeur de créatinine ou de CCR à 24 h selon différents $D G F$, durées d'exposition, fonctions rénales de base ou absorbants.

Conclusion Nous n'avons pas trouvé d'association entre l'utilisation du sévoflurane et des détériorations de la fonction rénale postopératoires par rapport aux autres agents utilisés pour le maintien de l'anesthésie. Les raisons scientifiques sur lesquelles repose la recommandation d'un DGF plus elevé lors de l'utilisation de sévoflurane doivent être réexaminées.
Keywords sevoflurane $\cdot$ nephrotoxicity $\cdot$ compound A . fresh-gas flow - fluoride ions

Sevoflurane is a widely used volatile anesthetic for anesthesia maintenance, but minimum fresh gas flows (FGFs) are recommended because of concerns of nephrotoxicity when used under low FGF conditions. ${ }^{1}$ While nephrotoxicity of inhaled anesthetics is well known with older agents such as methoxyflurane, ${ }^{2}$ such effects are largely theoretical with sevoflurane, with no definitive evidence regarding its nephrotoxicity. The two causes of concern regarding sevoflurane-induced nephrotoxicity are the relatively higher inorganic fluoride load on the kidneys secondary to its in vivo metabolism, and the ex vivo generation of compound $\mathrm{A}(\mathrm{CpdA})$, a substance generated following the reaction of sevoflurane with high alkalicontaining carbon dioxide $\left(\mathrm{CO}_{2}\right)$ absorbents, ${ }^{3}$ which is nephrotoxic in rodents. These concerns are presumed to be higher when sevoflurane is used in a circle ventilation circuit where a low FGF rate may result in accumulation of potentially toxic metabolites within the circuit. ${ }^{3}$

As a result, manufacturers have recommended various minimum FGF $^{1}$ rates with subsequent implications to the overall cost and the environmental footprint of anesthetic gases. $^{4-6}$ The product monograph for sevoflurane is different in different countries. In product monographs with FGF recommendations, these are tied to the presumed nephrotoxic potential of CpdA and not to fluoride levels or potential damage to organs other than the kidneys. Countries such as Germany, the United Kingdom, Ireland, or France, among others, have no defined minimum FGF recommendation., ${ }^{4-9}$ An FGF of 2 $\mathrm{L} \cdot \mathrm{min}^{-1}$, as is recommended in Canada, can increase the consumption and thus the cost and the environmental pollution from sevoflurane by a factor of four compared with use of minimal FGFs.

A recent systematic review of six studies on sevoflurane and isoflurane in patients with normal renal function did not find any differences in postoperative renal function between the two agents. ${ }^{10}$ Although several studies have investigated the use of sevoflurane on subsequent postoperative renal function over the past 30 years, this evidence has not yet been comprehensively reviewed. Hence, it is important to comprehensively review any association between the use of sevoflurane and subsequent renal function, especially factoring in the use of various FGFs, absorbents, and pre-existing renal dysfunction.

The primary aim of this study was to review the evidence of the impact of sevoflurane on postoperative renal function compared with alternative anesthetic maintenance agents deemed safe for the kidneys. The 
secondary aims of this study were to review the effect of sevoflurane on renal function under different FGFs, preexisting renal dysfunction, and different absorbents, as well as whether different FGFs and exposure durations have an effect on peak fluoride or CpdA levels.

\section{Methods}

\section{Literature review}

We followed the Cochrane handbook on systematic review of interventions for the conduct of the review, ${ }^{11}$ and we reported in accordance with the statement on the Preferred Reporting Items for Systematic Reviews and MetaAnalyses (PRISMA) (Fig. 1). ${ }^{12}$ Our search strategy covered the date of inception for each database to our final search and date of inclusion (23 April 2020). The databases included MEDLINE OVID (1946-present), Pubmed (1966-present), EMBASE (1947-present), the Cochrane Library-which included the Cochrane Database of Systematic Reviews (1995-present) and the Cochrane Central Register of Controlled Trials (CENTRAL)-CINAHL (1961-present), and Web of Science (1900-present). We did not apply any additional chronological parameters to our search. Additional search techniques included hand-searching the reference lists for further relevant studies and Google Scholar for grey literature. Key search terms included "sevoflurane", "nephrotoxicity", "renal function test" (RFT), "compound-A", "fluoride", "absorbent", "low-flow", "high-flow", "blood urea nitrogen" (BUN), "creatinine", and "creatinine clearance" (CCR). We did not exclude any languages because translation services were available in the university. The full search strategy is described in the eAppendix, available as Electronic Supplementary Material (ESM). A reference list was also created based on all articles the authors were able to discover independently and was then examined to ensure that all reference articles published by 23 April 2020 were retrieved in the searches. All titles and abstracts were independently screened by two authors (T.O. and R.S.) and only potentially relevant randomized-controlled trials (RCTs) were selected and reviewed by the two authors independently. Any disagreements were resolved by mutual discussion.

\section{Study selection}

Only human RCTs reporting on the use of sevoflurane $v s$ another agent used for anesthesia maintenance, with subsequent measurement of renal function parameters, were included in this review. We excluded RCTs that did not examine renal function following exposure to sevoflurane or did not use sevoflurane for anesthesia maintenance. We included trials on patients with stable preoperative renal dysfunction as we planned to perform subgroup analysis to detect any differences between patients with normal vs impaired renal function following exposure to sevoflurane.

We also collected any data on tubular function as assessed by urinary $\mathrm{N}$-acetyl glucosamine (U-NAG), kidney injury molecule-1, fatty-acid-binding proteins (FABP-H), U-NAG/creatinine ratio, glutathione Stransferase, and $\alpha$ and $B$ macroglobulin. Data were also reviewed pertaining to glomerular function as assessed by markers like cystatin-C or markers for both glomerular and tubular function such as urinary 24-hr albumin and urinary 24-hr protein. We further included specific gravity, $\mathrm{pH}$, and osmolality of urine as outcome measures. To look at the fluoride and CpdA load on the kidneys following sevoflurane use, all studies reporting these parameters with sevoflurane use were included in the analysis.

\section{Data extraction and primary endpoints}

Two investigators (K.N. and T.S.) independently reviewed and appraised each study prior to extracting the data on a standard data collection sheet. Any discrepancies between these two reviewers were resolved by discussion with a third investigator (R.S.). The time points of data collection were preoperative baseline values, early (four to six postoperative hours), and 24 and 48 postoperative hours with the 24-hr measurements for BUN, creatinine, and CCR being the primary endpoints. In trials not reporting the outcomes as mean (standard deviation [SD]) or not reporting at the pre-specified time points, the corresponding authors were contacted up to three times via email. When the measurements were reported as median (confidence interval $[\mathrm{CI}] /$ interquartile range $[\mathrm{IQR}] /$ standard error $[\mathrm{SE}]$ ) or as variance, these values were converted to mean (SD) based on previously published conversion formulas. ${ }^{13}$ All the values were converted to standard units of measurement before conducting statistical analysis. We followed the Cochrane Handbook for Systematic Reviews of Interventions recommendations when handling RCTs with more than two study arms by splitting the "shared" group into two or more groups with smaller sample sizes, and included two or more independent comparisons. ${ }^{11}$ If mean (SD) values could not be directly obtained either from the published manuscripts or from correspondence, the values were deduced from the figures-first manually and then reconfirmed using the Adobe Acrobat measurement tool and plot digitizer software (http://plotdigitizer.sourceforge. net/). 


\section{PRISMA Flow Diagram}

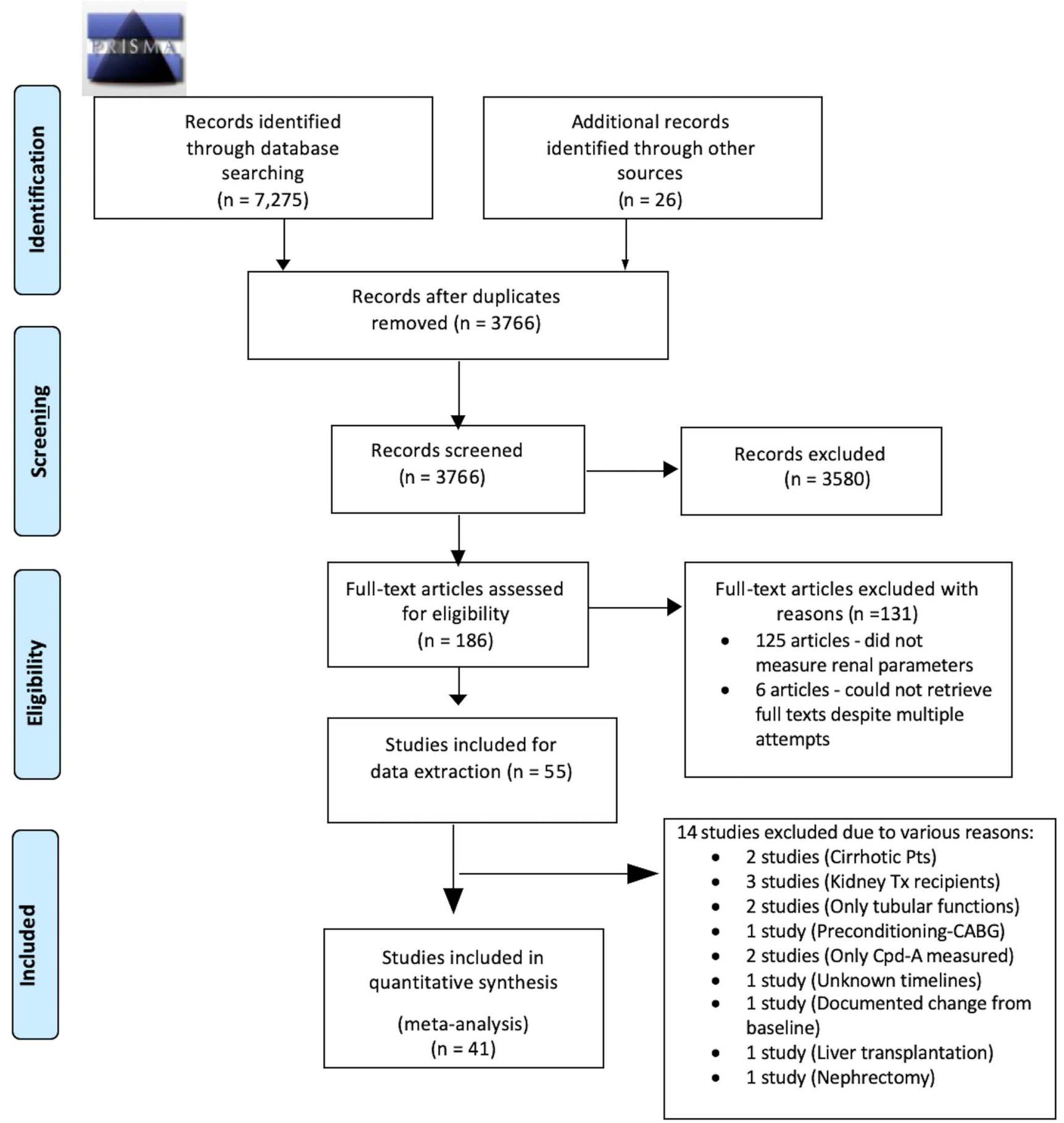

Fig. 1 PRISMA flow diagram

Risk of bias assessment

The quality of studies was appraised by the Cochrane Collaboration risk of bias instrument (version 5.0.1), which includes components to look for selection bias (based on random sequence generation and allocation concealment), performance bias (masking of both participants and investigators), detection bias (masking of evaluators), attrition bias (incomplete outcome data), reporting bias (selective outcome reporting), and other types of bias. Each component of individual RCTs was judged to be of low, unclear, or high risk of bias. When there were at least ten studies for meta-analysis, we assessed publication bias by 
visual assessment of funnel plot asymmetry. We did not quantify the degree of publication bias.

\section{Statistical analysis}

Statistical analysis was performed using Review Manager (RevMan; version 5.3. Copenhagen: The Nordic Cochrane Centre, The Cochrane Collaboration, 2014). Patients who received sevoflurane were allocated to the intervention group while patients receiving any anesthetic agent other than sevoflurane were considered as "alternative anesthetic" groups. Given our inclusion of a variety of different surgical populations and comparators, we expected clinical heterogeneity, so the meta-analysis was performed using the Mantel-Haenszel random-effects model. As all of our outcomes were continuous variables, the standardized mean difference (SMD) was calculated for each outcome and analyzed using forest plots for the magnitude and direction of effect. An SMD of $\leq 0.2$ was considered small, an SMD of 0.5 was considered medium, and an SMD $>0.8$ was considered large. ${ }^{14}$ The heterogeneity of outcomes across trials was assessed using the $\mathrm{I}^{2}$ statistic. We considered an $\mathrm{I}^{2}$ of $>50 \%$ to indicate significant heterogeneity and planned to address it by further exploration using subgroup analyses. Additionally, between-trial heterogeneity was planned as a sensitivity measure to see the effect of individual trials.

A priori subgroup analysis was planned to look for associations between the use of sevoflurane and renal function with respect to FGF, duration of anesthesia, type of absorbent used, and the presence or absence of prior renal impairment. The parameters of FGF and duration of anesthesia were dichotomized with FGF categorized as either low-flow anesthesia (LFA) ( $\leq 1 \mathrm{~L}$ FGF) or high-flow anesthesia (HFA) $(\geq 1$ L FGF) while the duration of anesthesia was categorized as $\leq$ three hours or $\geq$ three hours. Further exploration of heterogeneity was planned via meta-regression if there were significant differences in outcomes between sevoflurane and alternative anesthetics or if significant heterogeneity was present. Meta-regression models with plots were generated using OpenMeta[Analyst] software (http://www.cebm.brown. edu/openmeta/) to explore the use of sevoflurane and subsequent fluoride and $\mathrm{CpdA}$ levels and their association with the FGF and the duration of exposure. We did not perform meta-analysis for tubular function tests; these outcomes were summarized descriptively in the review.

\section{Quality of evidence}

We rated the confidence in the estimate of effects based on a scoring system that, apart from the risk of bias, includes assessments for inconsistency, indirectness, imprecision, and publication bias. We utilized the GRADE-Pro tool to score the individual components and based on the above assessments, we classified the strength of evidence as strong, moderate, low, or very low quality.

Patient and public involvement

Patients and/or the public were not involved in the creation of this systematic review and meta-analysis as the format did not lend itself to outside participation.

\section{Results}

A total of 3,766 records were identified through database searches and cross referencing for the initial screening. After review of the abstracts, 3,580 studies were excluded for various reasons, and $186 \mathrm{RCTs}$ were considered for full-text assessment. Of these 186 RCTs, a further 131 articles were excluded from quantitative synthesis (125 articles were excluded as they did not measure renal parameters as a part of their outcomes and six articles were excluded as we could not retrieve the full texts despite multiple attempts). ${ }^{15-20}$ Twelve other studies were also excluded $^{21-32}$ (Fig. 1; PRISMA diagram) and data were extracted from 41 RCTs. ${ }^{33-73}$ There were no disagreements between the authors regarding study selection, but additional articles were retrieved by a single reviewer (R.S.) through cross referencing. Data extracted by the two reviewers (K.N. and T.S.) were crosschecked for accuracy by another reviewer (R.S.) and any discrepancies in data collection or conversion were resolved mutually. Three studies were translated into English. ${ }^{41,53,66}$

\section{Study characteristics}

Characteristics of the included studies and the assessed outcomes are summarized in Table 1. The outcomes assessed in these studies other than those outlined in Table 1 include urinary albumin, ${ }^{53}$ urinary alpha macroglobulin, ${ }^{34,58}$ glutathione $\mathrm{S}$-transferases-alpha, ${ }^{34,50}$ and serum osmolality, ${ }^{42,61,67,73}$ There was significant variability among the included trials in terms of patient population, type of surgery, presence of prior renal impairment, FGF, duration of exposure, and the use of $\mathrm{CO}_{2}$ absorbents. Conversions to $\mathrm{mg} \cdot \mathrm{dL}^{-1}$ were done for creatinine ${ }^{24,34,55,61,64,68}$ and $\mathrm{BUN}^{24,55,61,64,67,70}$ from nonSI units of measurements while conversions to mean (SD) for central tendency and dispersions were needed in four more studies. ${ }^{57,64,68,70}$ Creatinine values were extrapolated from graphical data in seven studies, ${ }^{49,51,54,56,69,71,72}$ BUN in eight studies, ${ }^{43,49,51,54,56,69,71,72}$ CCR in eight 


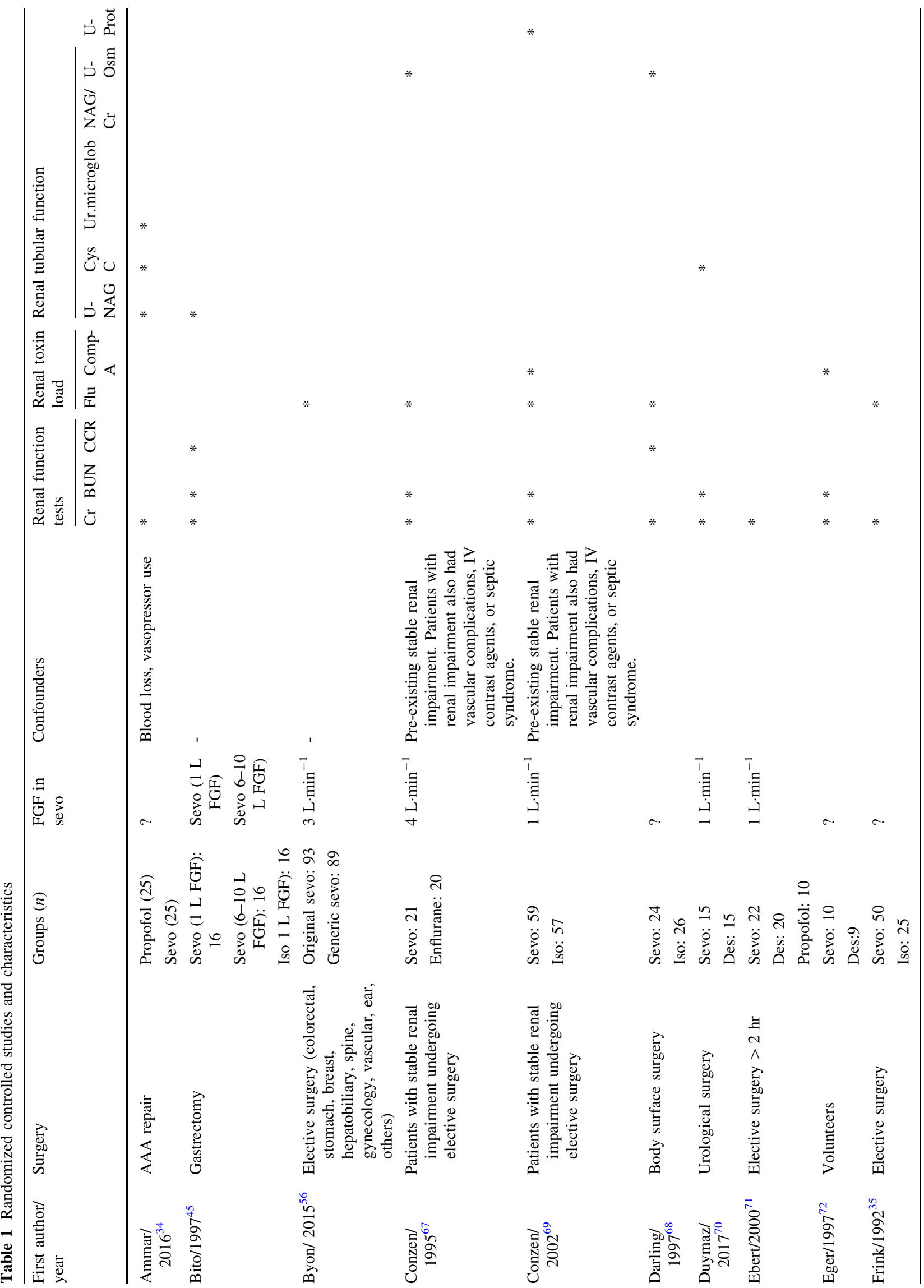




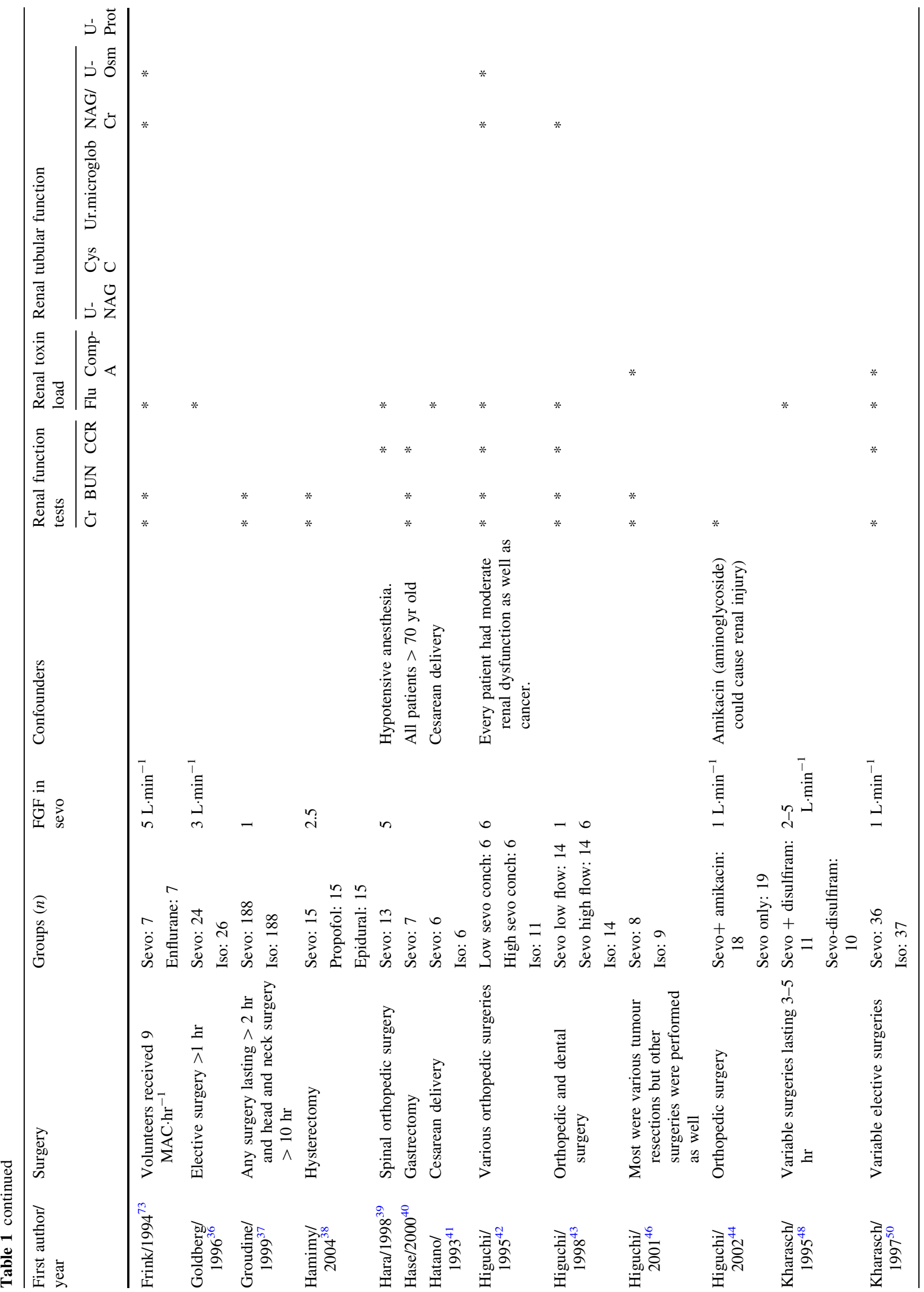




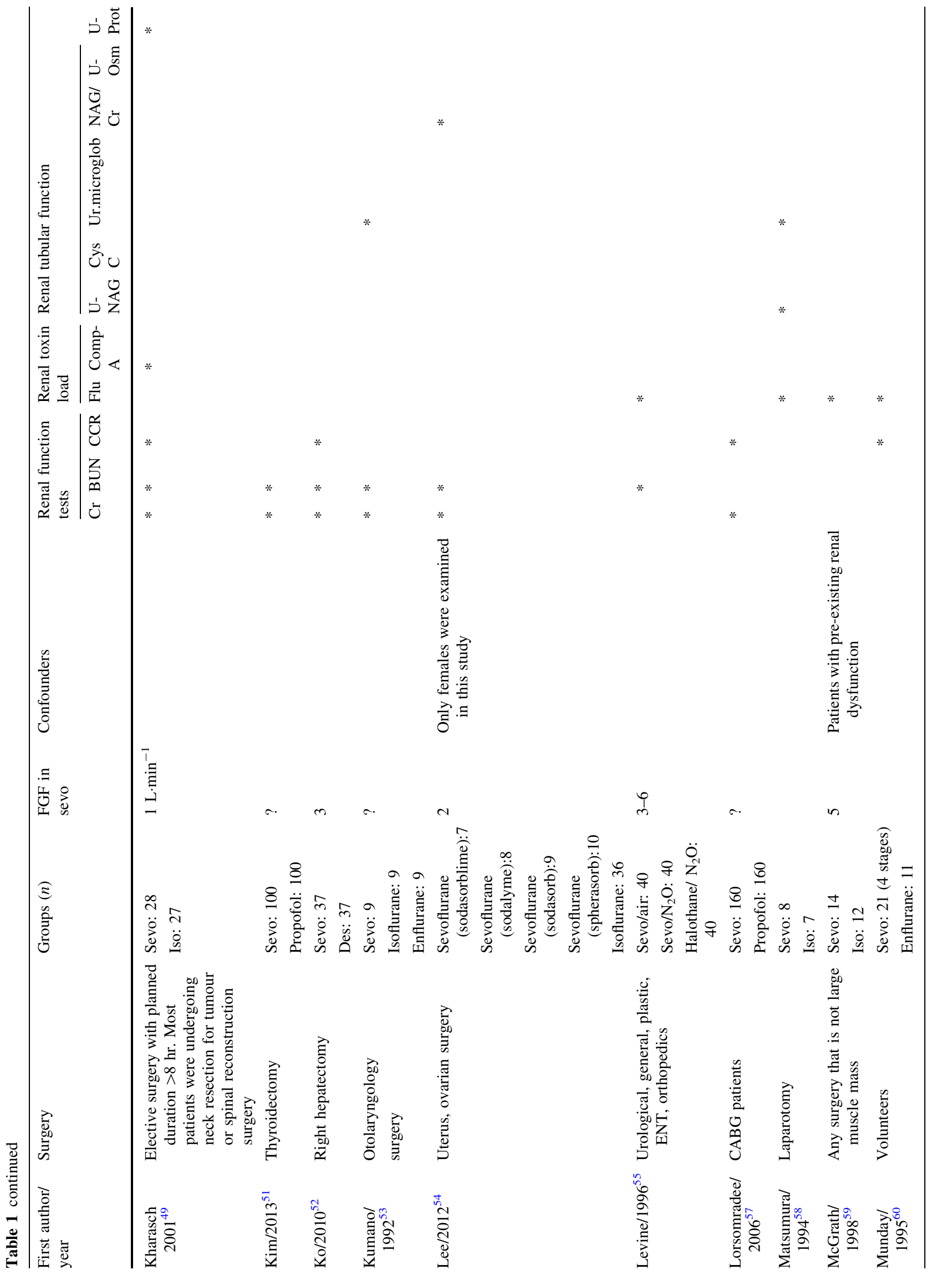




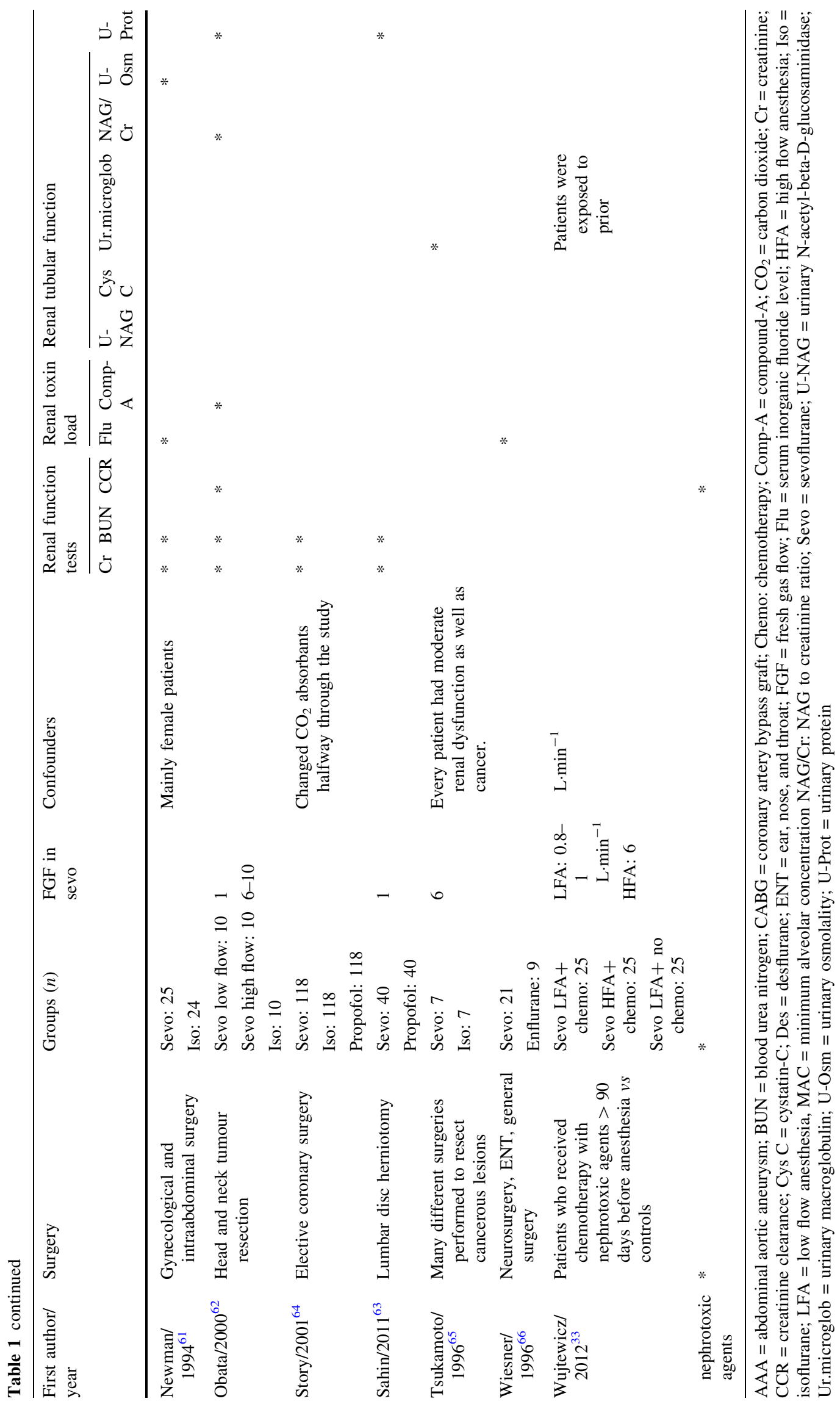




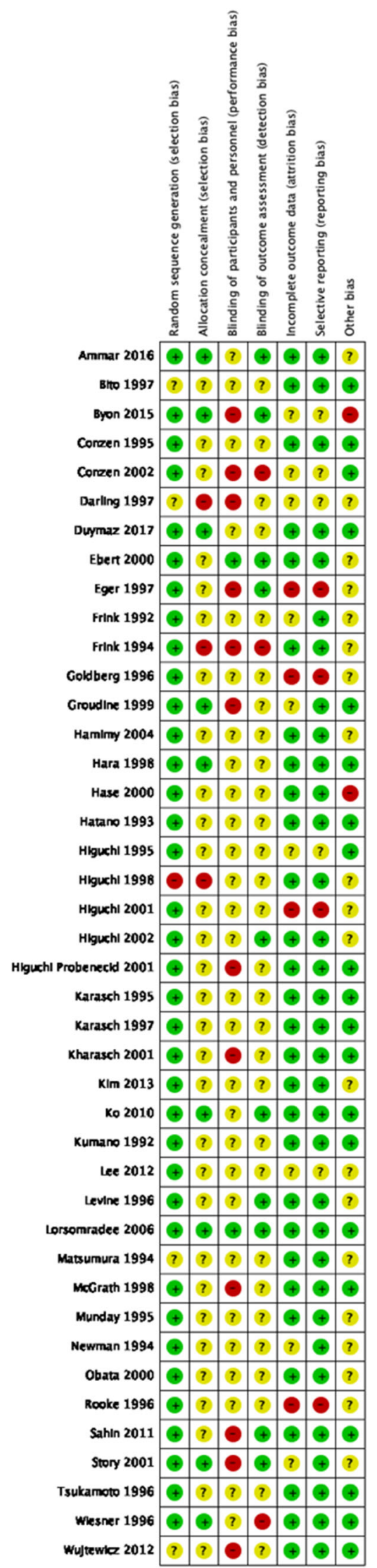

4Fig. 2 Risk of bias rating for the included trials

studies, ${ }^{39,40,43,49,53,56,60,68}$ and peak serum fluoride in 18 studies. $^{35,36,39,40,42,43,48-50,55,58-61,65,68,69,73}$

Risk of bias assessment

The risk of bias rating for the included trials is given in Fig. 2 and the risk of bias is summarized in Fig. 3. All the included trials were RCTs. All but four studies ${ }^{43,45,58,68}$ addressed random sequence generation, nine studies adequately addressed allocation concealment, ${ }^{34,37,39,52,56,57,64,66,70}$ two trials explicitly stated blinding procedures, ${ }^{57,71}$ ten studies adequately addressed detection bias, ${ }^{34,44,52,55-57,63,64,71,72}$ and 29 trials accounted for all patients in the trial. $^{34,38-41,43-45,47-53,55,57-60,62-65,67,69-71,73}$

\section{Primary outcome}

The primary outcome of BUN, creatinine, and CCR to assess the renal function at 24 postoperative hours were not impaired following the use of sevoflurane $v s$ alternative anesthetics. In 24 studies $(n=2,024)$, the effect of sevoflurane $(n=1,015)$ on serum creatinine was compared with that in the alternative anesthetic group ( $n$ $=1,009)$ as noted by an SMD of $0.04 \mathrm{mg} \cdot \mathrm{dL}^{-1}(95 \% \mathrm{CI}$, -0.06 to 0.13$)$ (Fig. 4). In 21 studies $(n=1,529)$ evaluating the effect of sevoflurane $(n=731)$ vs alternative anesthetic $(n=798)$ on BUN, no differences were noted (SMD, 0.06; $95 \% \mathrm{CI},-0.04$ to 0.16 ) (Fig. 5). A total of 12 studies ( $n=$ 728) evaluated the effect of sevoflurane $(n=385)$ vs alternative anesthetic $(n=343)$ on CCR and showed no differences between the groups (SMD, 0.14; 95\% CI, -0.09 to 0.37 ) (Fig. 6).

Subgroup analysis for the primary outcome

Subgroup analysis was performed for the primary outcome variables to detect any effect of sevoflurane under different FGF, types of absorbents, duration of anesthetic exposure, and the presence of stable renal dysfunction on renal function parameters (Figs 7-16). Although there seemed to be a trend for lower creatinine and BUN concentrations in the alternative anesthetic group in patients with preexisting renal impairment, the pooled estimate of effect for the use of sevoflurane on serum creatinine crossed the line of null effect (Figs 8 and 11).

The FGF is thought to be important during sevoflurane use. The subgroup analysis with the FGF dichotomized as $\leq 1 \mathrm{~L} \mathrm{FGF} v s>1 \mathrm{~L} \mathrm{FGF}$ revealed that the pooled estimate 
Fig. 3 Risk of bias graph: authors' judgements about each risk of bias item for included studies
Random sequence generation (selection bias)

Allocation concealment (selection bias)

Blinding of participants and personnel (performance bias)

Blinding of outcome assessment (detection bias)

Incomplete outcome data (attrition bias)

Selective reporting (reporting bias)

Other bias

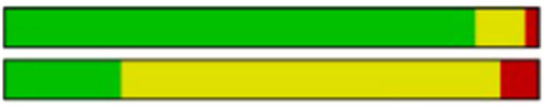

L

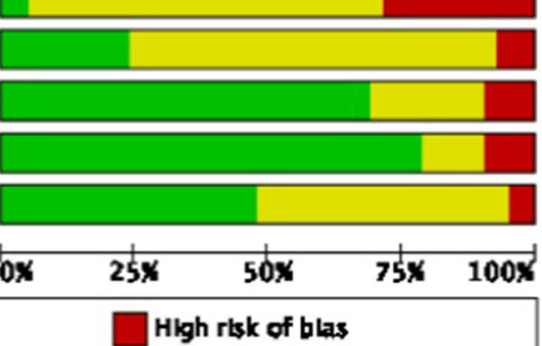

Low rksk of blas

Unclear rtsk of blas

High rtsk of blas

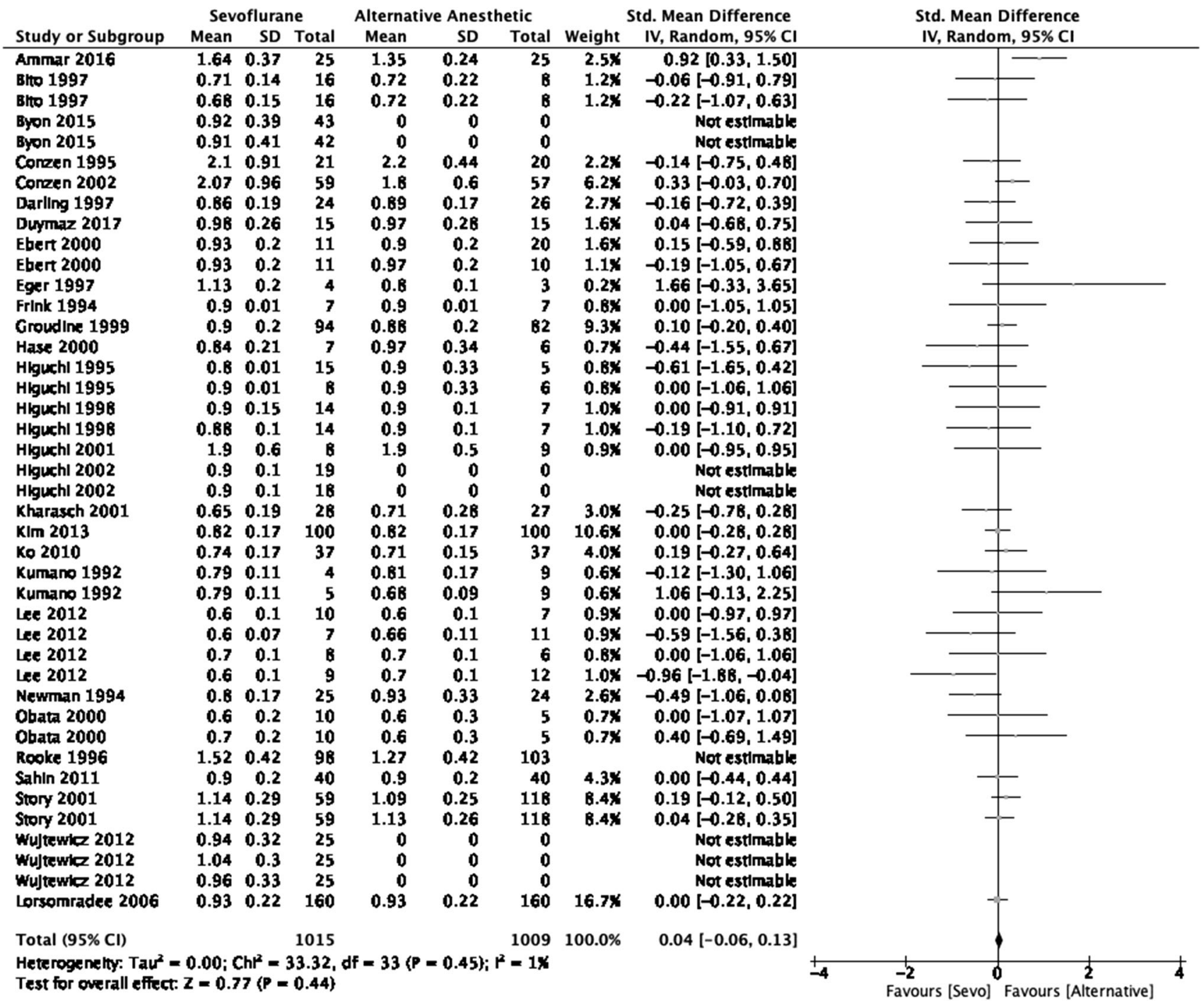

Fig. 4 Forest plot showing the overall effect of sevoflurane $v s$ an alternative anesthetic agent on serum creatinine measured at 24 postoperative hours 


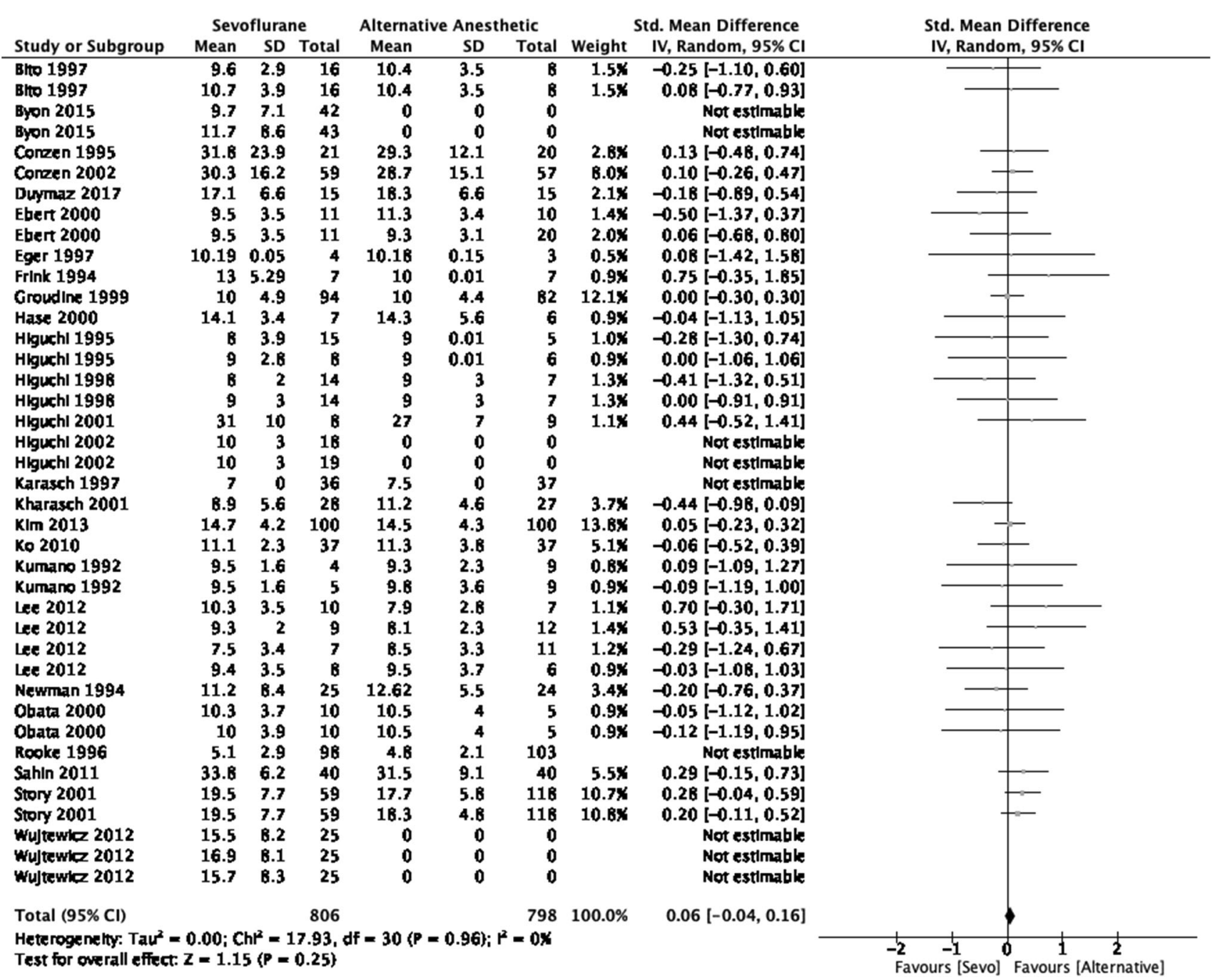

Fig. 5 Forest plot showing the overall effect of sevoflurane $v s$ an alternative anesthetic agent on blood urea nitrogen (BUN) measured at 24 postoperative hours

crossed the line of null effect, denoting no significant benefit of sevoflurane or the alternative anesthetic on the 24-hr measurements of CCR (12 studies with 427 subjects; six studies employing $\leq 1$ L FGF; and six studies employing $>1$ L FGF), creatinine (19 studies with 1,202 subjects; nine studies employing $\leq 1 \mathrm{~L} \mathrm{FGF;} \mathrm{and} \mathrm{ten}$ studies employing $>1$ L FGF), or the BUN concentration (12 studies with 1,232 subjects; 11 studies employing $\leq 1$ L FGF; and nine studies employing $>1$ L FGF) (Figs 7, 12, and 15). A similar null effect was observed on subgroup analysis for the effect of duration of exposure $(\leq$ three hours $v s>$ three hours) and the use of type of absorbents on subsequent measurement of CCR, creatinine, or BUN values measured at 24 postoperative hours (Figs 9, 10, 13, 14, and 16).

Subgroup analysis for CCR was performed only for FGF and absorbent type as there was an inadequate number of studies looking at CCR after prolonged anesthetic duration. The CCR values were higher in the sevoflurane group with 


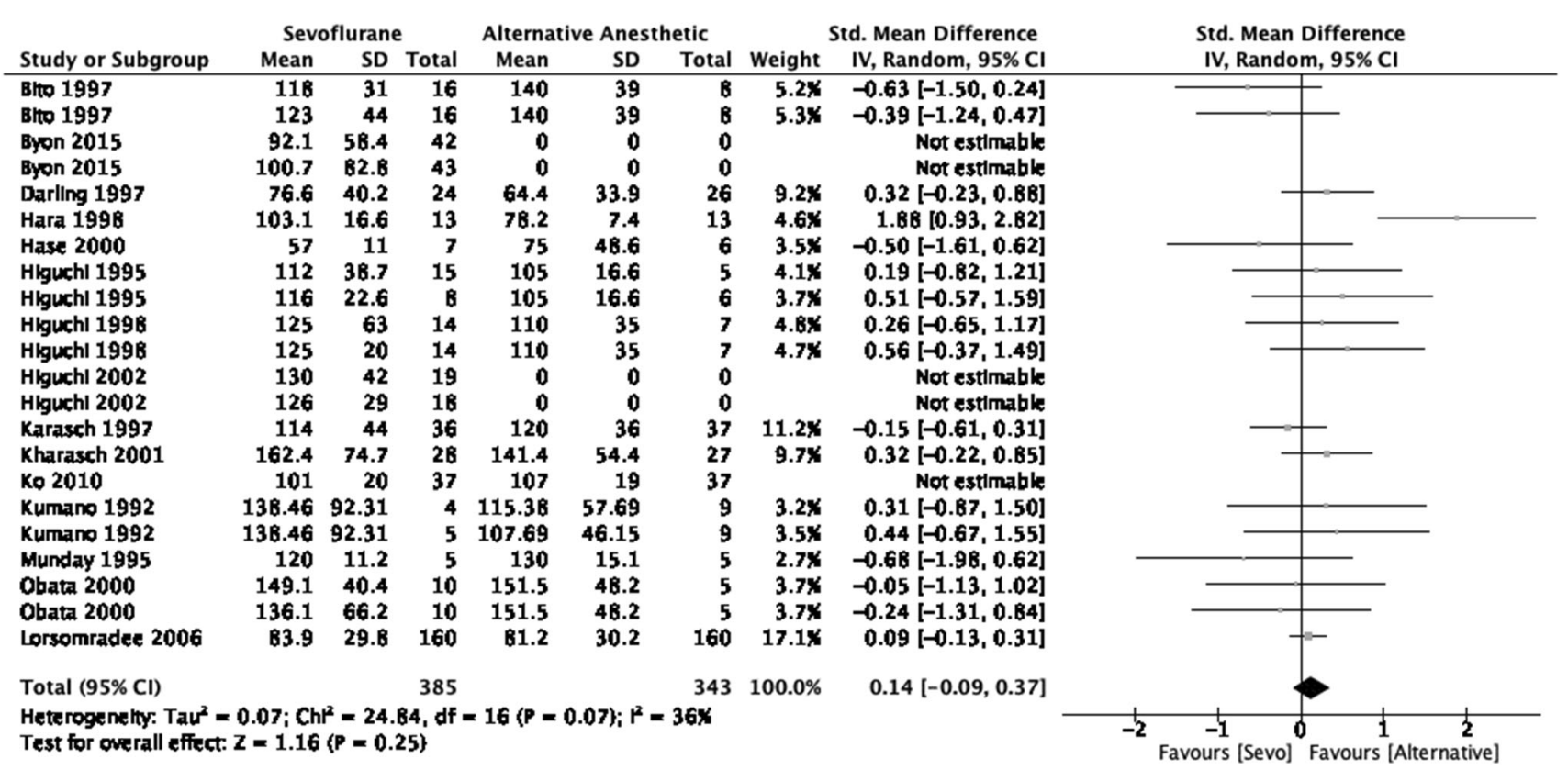

Fig. 6 Forest plot showing the overall effect of sevoflurane $v s$ an alternative anesthetic agent on creatinine clearance (CCR) measured at 24 postoperative hours

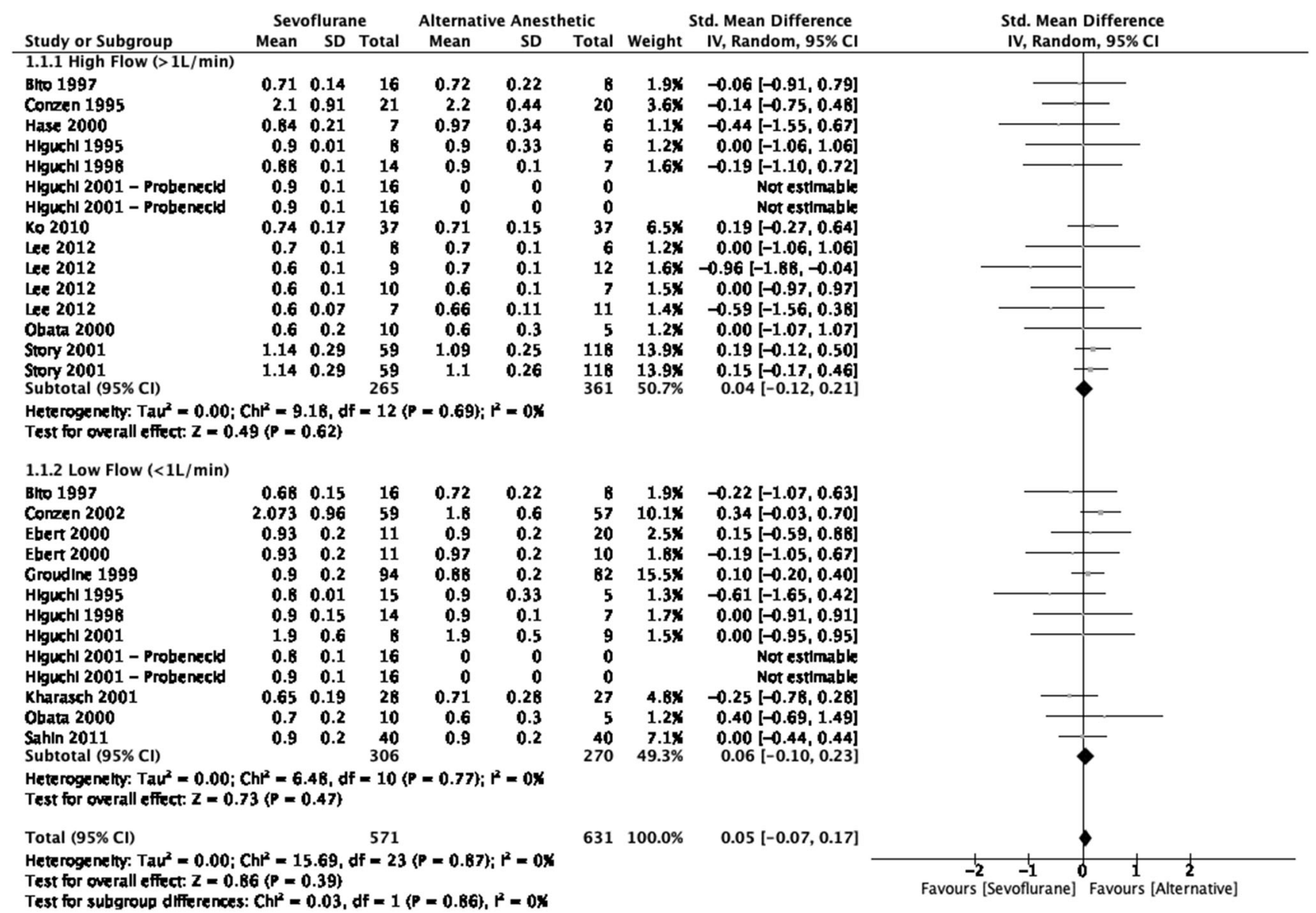

Fig. 7 Subgroup analysis showing the effect of sevoflurane $v s$ an alternate anesthetic agent on serum creatinine measured at 24 postoperative hours when delivered at low fresh-gas flow $(\mathrm{FGF})(\leq 1 \mathrm{~L})$ or high FGF $(>1 \mathrm{~L})$ 


\begin{tabular}{|c|c|c|c|c|c|c|c|c|c|c|c|}
\hline \multirow[b]{2}{*}{ Study or Subgroup } & \multicolumn{3}{|c|}{ Sevoflurane } & \multicolumn{3}{|c|}{ Alternative Anesthetic } & \multicolumn{2}{|r|}{ Std. Mean Difference } & \multirow{2}{*}{\multicolumn{3}{|c|}{$\begin{array}{l}\text { Std. Mean Difference } \\
\text { IV, Random, } 95 \% \mathrm{Cl}\end{array}$}} \\
\hline & Mean & SD & Total & Mean & SD & Total & Weight & IV, Random, 95\% CI & & & \\
\hline \multicolumn{12}{|c|}{ 1.2.1 Previous Renal Impairment } \\
\hline Conzen 1995 & 2.1 & 0.91 & 21 & 2.2 & 0.44 & 20 & 4.4\% & $-0.14[-0.75,0.48]$ & & - & \\
\hline Conzen 2002 & 2.073 & 0.96 & 59 & 1.8 & 0.6 & 57 & $12.4 \times$ & $0.34[-0.03,0.70]$ & & 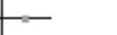 & \\
\hline Hguchl 2001 & 1.9 & 0.6 & $\begin{array}{r}8 \\
88\end{array}$ & 1.9 & 0.5 & $\begin{array}{r}9 \\
86\end{array}$ & $\begin{array}{l}1.8 \mathrm{BX} \\
18.6 \%\end{array}$ & $0.00[-0.95,0.95]$ & & & \\
\hline \multicolumn{12}{|c|}{$\begin{array}{l}\text { Heterogenelty: } \text { Tau }^{2}=0.00 ; \mathrm{Ch}^{2}=1.86 \text {, df }=2\langle\mathrm{P}=0.39) ; \mathrm{P}^{2}=0 \mathrm{X} \\
\text { Test for overall effect: } \mathrm{Z}=1.26(\mathrm{P}=0.21\}\end{array}$} \\
\hline \multicolumn{12}{|c|}{ 1.2.2 No Previous Renal Impairment } \\
\hline Bho 1997 & 0.68 & 0.15 & 16 & 0.72 & 0.22 & $\mathbf{B}$ & $2.3 \mathbf{x}$ & $-0.22[-1.07,0.63]$ & & - & \\
\hline Blto 1997 & 0.71 & 0.14 & 16 & 0.72 & 0.22 & $\mathbf{B}$ & $2.3 \mathbf{x}$ & $-0.06[-0.91,0.79]$ & & & \\
\hline Darling 1997 & 0.86 & 0.19 & 24 & 0.89 & 0.17 & 26 & $5.4 x$ & $-0.16[-0.72,0.39]$ & & - & \\
\hline Ebert 2000 & 0.93 & 0.2 & 11 & 0.9 & 0.2 & 20 & 3.1\% & $0.15[-0.59,0.8 B]$ & & & \\
\hline Ebert 2000 & 0.93 & 0.2 & 11 & 0.97 & 0.2 & 10 & $2.3 \mathbf{x}$ & $-0.19[-1.05,0.67]$ & & - & \\
\hline Hkguchl 1995 & 0.9 & 0.01 & $\mathbf{B}$ & 0.9 & 0.33 & 6 & $1.5 \mathrm{x}$ & $0.00[-1.06,1.06]$ & & & \\
\hline Hoguchl 1995 & 0.8 & 0.01 & 15 & 0.9 & 0.33 & 5 & $1.6 x$ & $-0.61[-1.65,0.42]$ & & - & \\
\hline Higuchl 1998 & 0.9 & 0.15 & 14 & 0.9 & 0.1 & 7 & $2.0 \mathrm{x}$ & $0.00[-0.91,0.91]$ & & & \\
\hline Hlguxhl 1998 & $0.8 \mathrm{~B}$ & 0.1 & 14 & 0.9 & 0.1 & 7 & $2.0 \mathrm{x}$ & $-0.19[-1.10,0.72]$ & & - & \\
\hline Kharasch 2001 & 0.65 & 0.19 & 28 & 0.71 & 0.28 & 27 & $5.9 x$ & $-0.25[-0.7 B, 0.2 B]$ & & - & \\
\hline $\operatorname{KIm} 2013$ & 0.82 & 0.17 & 100 & 0.82 & 0.17 & 100 & $21.6 \times$ & $0.00[-0.2 B, 0.2 B]$ & & - & \\
\hline Ko 2010 & 0.74 & 0.17 & 37 & 0.71 & 0.15 & 37 & B.0x & $0.19[-0.27,0.64]$ & & & \\
\hline Lee 2012 & 0.7 & 0.1 & B & 0.7 & 0.1 & 6 & $1.5 \%$ & $0.00[-1.06,1.06]$ & & & \\
\hline Lee 2012 & 0.6 & 0.1 & 9 & 0.7 & 0.1 & 12 & $2.0 \%$ & $-0.96[-1.8 B,-0.04]$ & & & \\
\hline Lee 2012 & 0.6 & 0.1 & 10 & 0.6 & 0.1 & 7 & $1.8 \times$ & $0.00[-0.97,0.97]$ & & & \\
\hline Lee 2012 & 0.6 & 0.07 & 7 & 0.66 & 0.11 & 11 & $1.8 \%$ & $-0.59[-1.56,0.38]$ & & - & \\
\hline Newman 1994 & 0.8 & 0.17 & 25 & 0.93 & 0.33 & 24 & $5.1 \mathrm{x}$ & $-0.49[-1.06,0.08]$ & & & \\
\hline Obata 2000 & 0.6 & 0.2 & 10 & 0.6 & 0.3 & 5 & $1.4 \mathrm{x}$ & $0.00[-1.07,1.07]$ & & & \\
\hline Obata 2000 & 0.7 & 0.2 & 10 & 0.6 & 0.3 & 5 & $1.4 \times$ & $0.40[-0.69,1.49]$ & & & \\
\hline Rooke 1996 & 1.52 & 0.42 & 98 & 1.27 & 0.42 & 103 & & Not estimable & & & \\
\hline Sahln 2011 & 0.9 & 0.2 & 40 & 0.9 & 0.2 & 40 & 8.6\% & $0.00[-0.44,0.44]$ & & - & \\
\hline Story 2001 & 1.14 & 0.29 & 59 & 1.1 & 0.26 & 118 & & Not estimable & & & \\
\hline Story 2001 & 1.14 & 0.29 & $\begin{array}{r}59 \\
413\end{array}$ & 1.09 & 0.25 & 118 & $81.4 \%$ & Not estimable & & & \\
\hline \multirow{2}{*}{\multicolumn{12}{|c|}{$\begin{array}{l}\text { Heterogenelty: } \text { Tau }^{2}=0.00 ; C h h^{2}=11.21, d f=19(P=0.92) ; P^{2}=0 x \\
\text { Test for overall effect: } Z=1.30(P=0.19)\end{array}$}} \\
\hline & & & & & & & & & & & \\
\hline \multirow{2}{*}{\multicolumn{9}{|c|}{ 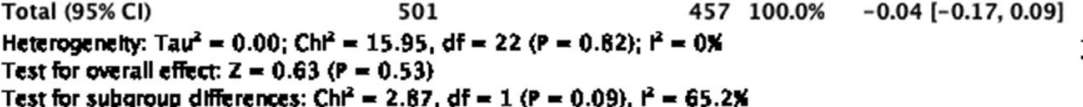 }} & & & \\
\hline & & & & & & & & & $\stackrel{-1}{-2}$ & 0 & $\sum_{\text {ernative] }}^{1}$ \\
\hline
\end{tabular}

Fig. 8 Subgroup analysis showing the effect of sevoflurane $v s$ an alternate anesthetic agent on serum creatinine measured at 24 postoperative hours when delivered to patients with or without prior stable renal dysfunction

the use of soda lime while this was not the case with baralyme (Figs 15 and 16).

Renal function tests at other time points

Renal function tests of creatinine, BUN, and CCR did not reveal differences between sevoflurane or alternative anesthetics either at early postoperative or 48 postoperative hour measurements. Postoperative creatinine concentration $\left(\mathrm{mg} \cdot \mathrm{dL}^{-1}\right)$ was reported in eight studies. There were no differences between sevoflurane and alternative anesthetics (SMD, $0.10 ; 95 \% \mathrm{CI},-0.23$ to 0.43 ) (ESM eFigs 1 and 2). At 48 postoperative hours, a pooled estimate of serum creatinine from 16 studies $(n=1,510)$ also showed no difference (SMD, $0.08 ; 95 \% \mathrm{CI},-0.03$ to 0.18). The BUN values $\left(\mathrm{mg} \cdot \mathrm{dL}^{-1}\right)$ did not differ with sevoflurane in the early postoperative period (SMD, -0.15 ; $95 \% \mathrm{CI},-0.72$ to 0.42 ) or at 48 postoperative hours $v \mathrm{~s}$ alternative anesthetic (SMD, 0.07; 95\% CI, -0.04 to 0.18) (ESM eFigs 3 and 4). Findings for CCR were similar (ESM eFigs 5 and 6). Higher baseline concentrations of BUN and creatinine were noted for patients with pre-existing stable renal dysfunction, but there was no difference following sevoflurane anesthesia. Unusually low values of CCR were reported in the postoperative measurements in one study, ${ }^{40}$ more so in the alternative anesthetic group 


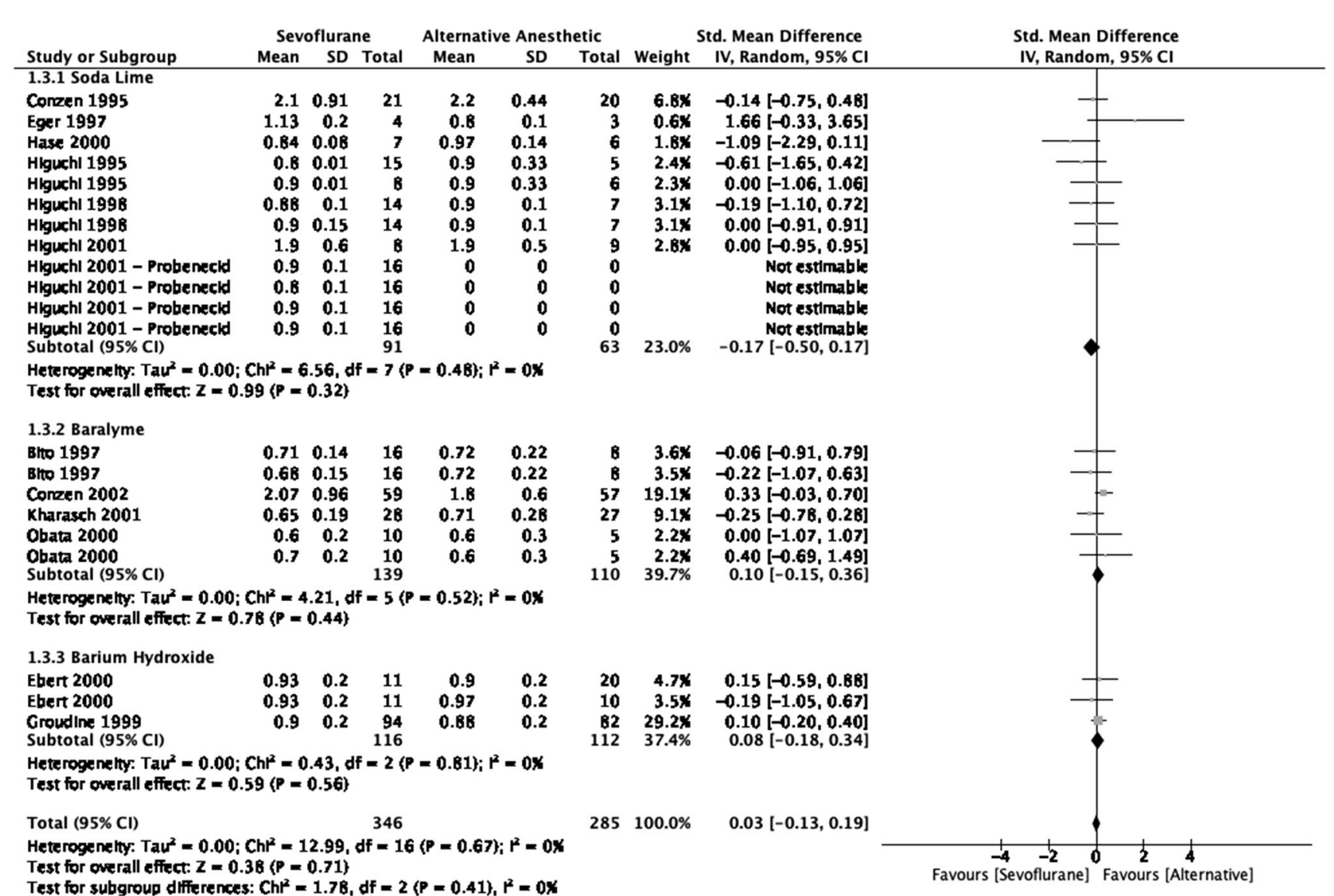

Fig. 9 Subgroup analysis showing the effect of sevoflurane $v s$ an alternate anesthetic agent on the serum creatinine measured at 24 postoperative hours when used in conjunction with various absorbents

than the sevoflurane group and this could be related to the elderly population included in the study or the effect of epidural analgesia, although the 24-hr CCR values showed no difference between sevoflurane and alternative anesthetics.

Fluoride levels

Twenty-three studies selected in our review evaluated the effect of sevoflurane on free fluoride load on the kidneys. $^{35-37,39-43,48,49,55,56,58-62,65-69,73}$ In trials comparing sevoflurane with other halogenated agents, sevoflurane was associated with a higher fluoride load $\left(\mu \mathrm{mol} \cdot \mathrm{L}^{-1}\right)$ at 24 postoperative hours in 15 studies (SMD, 6.16; $95 \%$ CI, 4.42 to 7.90 ) (ESM eFig. 7) and at $48 \mathrm{hr}$ in nine studies (ESM eFig. 8) (SMD, 4.35; 95\% CI, 1.75 to 6.96).

Peak plasma fluoride and peak CpdA

The pooled estimate of peak serum fluoride (mean) following sevoflurane from all the studies was 35.08 (95\% CI, 31.52 to 38.64$) \mu \mathrm{mol} \cdot \mathrm{L}^{-1}$ (ESM eFig. 9) and was higher compared with other halogenated agents (Fig. 17). 


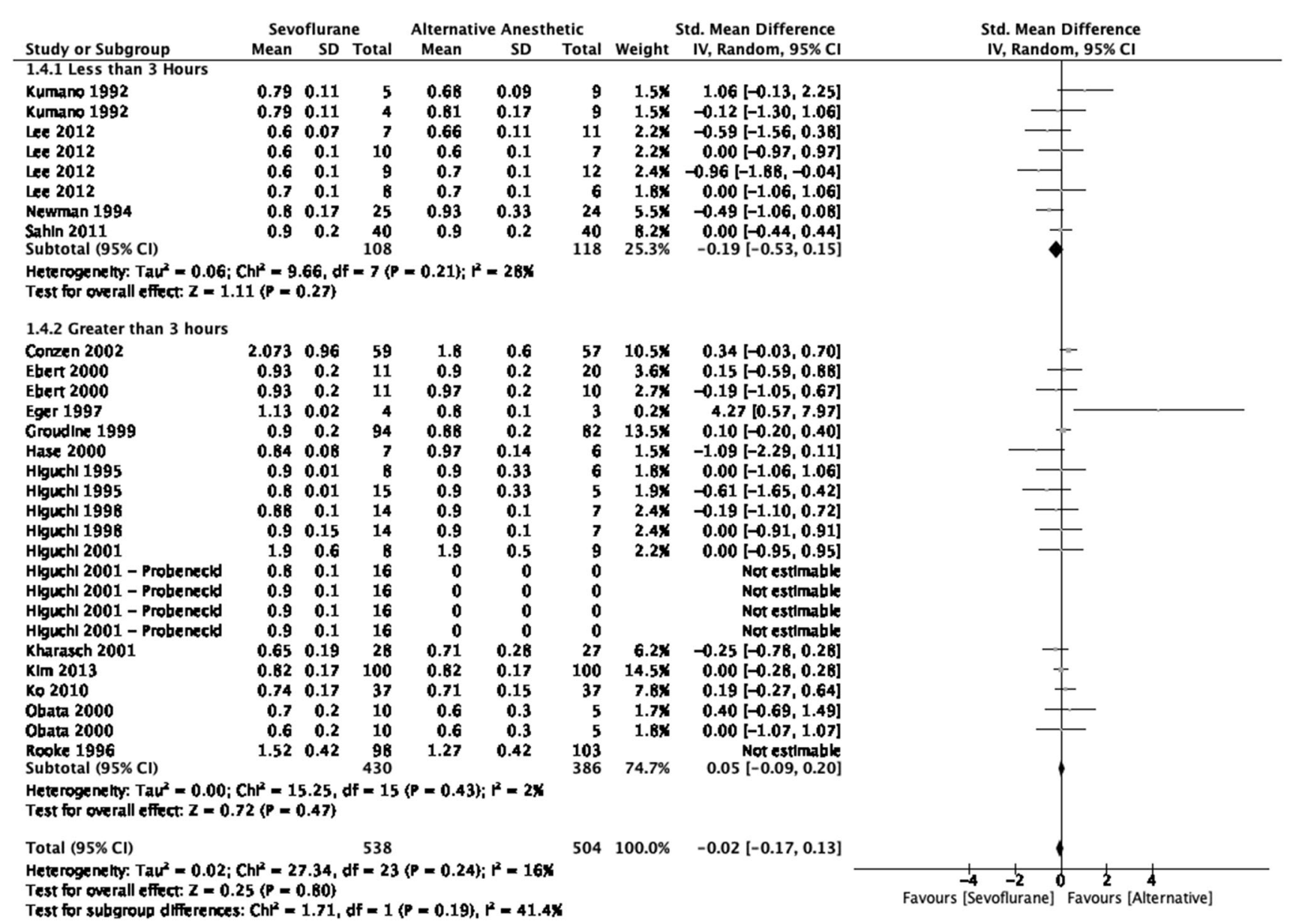

Fig. 10 Subgroup analysis showing the effect of sevoflurane $v s$ an alternate anesthetic agent on the serum creatinine measured at 24 postoperative hours when the duration of exposure is dichotomized to $\leq$ or $>$ three hours

The effect of FGF and the duration of exposure on peak fluoride levels was measured using meta-regression and presented as bubble plot graphs. Fluoride load was higher with increasing exposure (duration being the covariate) (ESM eFig. 10) but not with an increasing FGF (FGF being the covariate) (ESM eFig. 11).

The effects of sevoflurane on maximum CpdA levels were assessed in ten studies. ${ }^{31,44,45,47,49,50,56,62,69,72}$ The pooled mean peak CpdA levels was 25.90 (95\% CI, 21.46 to 30.35 ) as assessed across a variety of durations and FGF (ESM eFig. 12). Higher FGF was associated with lower CpdA level (ESM eFig. 13) but no association was noted with duration of exposure (ESM eFig. 14).

Tests of tubular function

Despite inconsistencies in the units of measurements, all studies were consistent in noting a lack of significant derangement in tubular function with the use of sevoflurane compared with alternative anesthetics (Table 2). Only one study noted sustained effects on glomerular, proximal, and distal tubular function after prolonged exposure to sevoflurane but not with desflurane. ${ }^{72}$ There was no summation of these measures in this study, but the tubular and glomerular function were documented on a case by case basis.

Summary of findings

Based on the cumulative strength of evidence assessed as per the GRADE recommendations, we can conclude with low to moderate certainty that sevoflurane use did not disturb renal function measures of creatinine, BUN, and CCR (Table 3). We can conclude with certainty that peak and 24-hr fluoride levels are higher when sevoflurane is used compared with when other volatile anesthetics are used. 


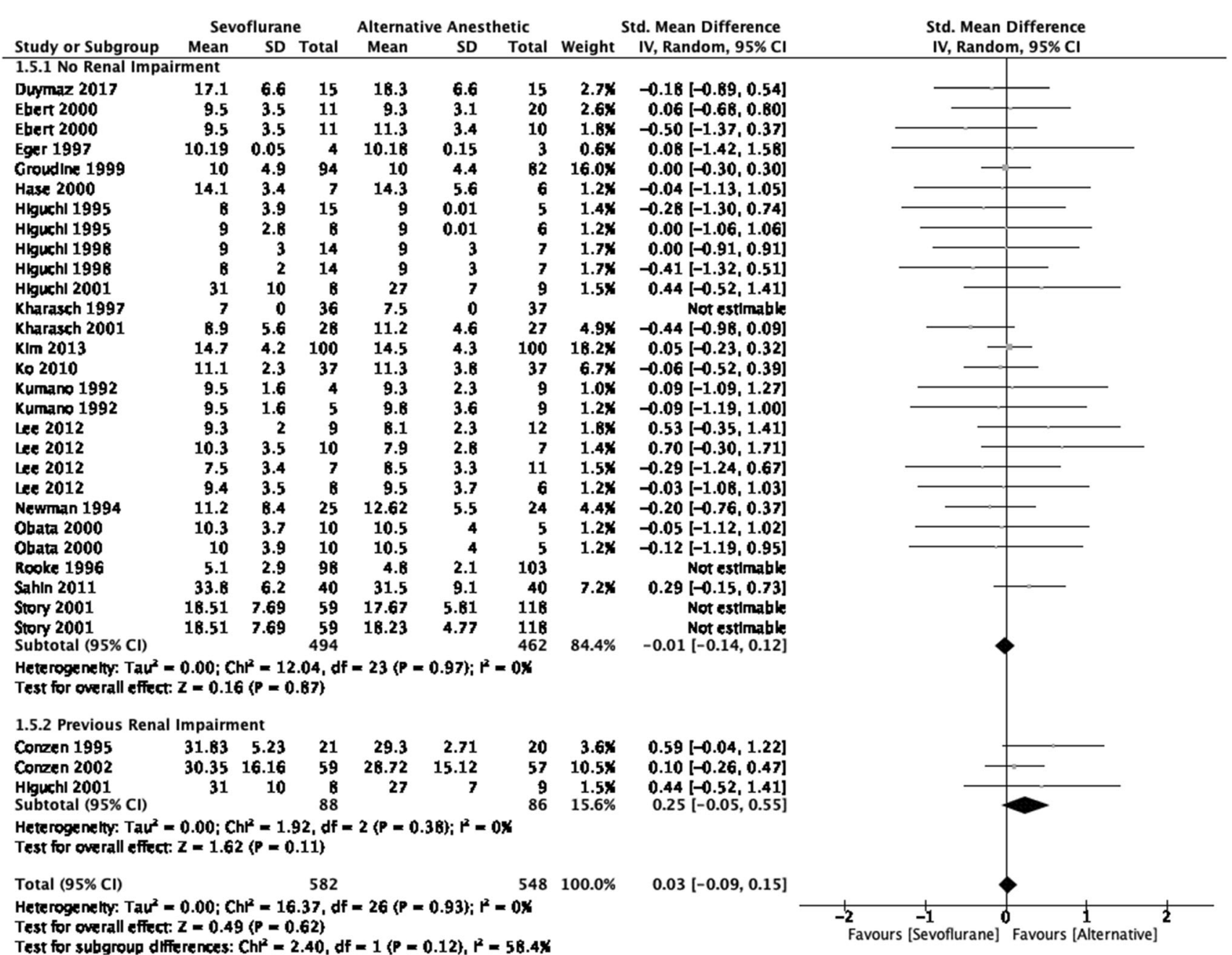

Fig. 11 Subgroup analysis showing the effect of sevoflurane $v s$ an alternate anesthetic agent on blood urea nitrogen (BUN) measured at 24 postoperative hours when delivered to patients with or without prior stable renal dysfunction

\section{Discussion}

Our systematic review and meta-analysis of randomizedcontrolled studies showed that variables used to assess renal function (i.e., creatinine, CCR, and BUN) at 24 postoperative hours did not differ significantly following the use of sevoflurane compared with alternative anesthetics. Although the quality of evidence is moderate, sevoflurane usage assessed in subgroups utilizing LFA, in patients with pre-existing renal impairment, and across a wide variety of $\mathrm{CO}_{2}$ absorbents showed comparable renal function with that of alternative anesthetics. This has important economic and environmental consequences as well as implications for clinical practice.

Sevoflurane was first approved for human use in Japan in $1990^{74}$ and has shown significant benefits over other volatile anesthetics. ${ }^{75}$ Uncertainty has remained in regard to potential nephrotoxicity in humans. The main concerns have been the higher fluoride load and CpdA generation, both of which have been associated with direct 


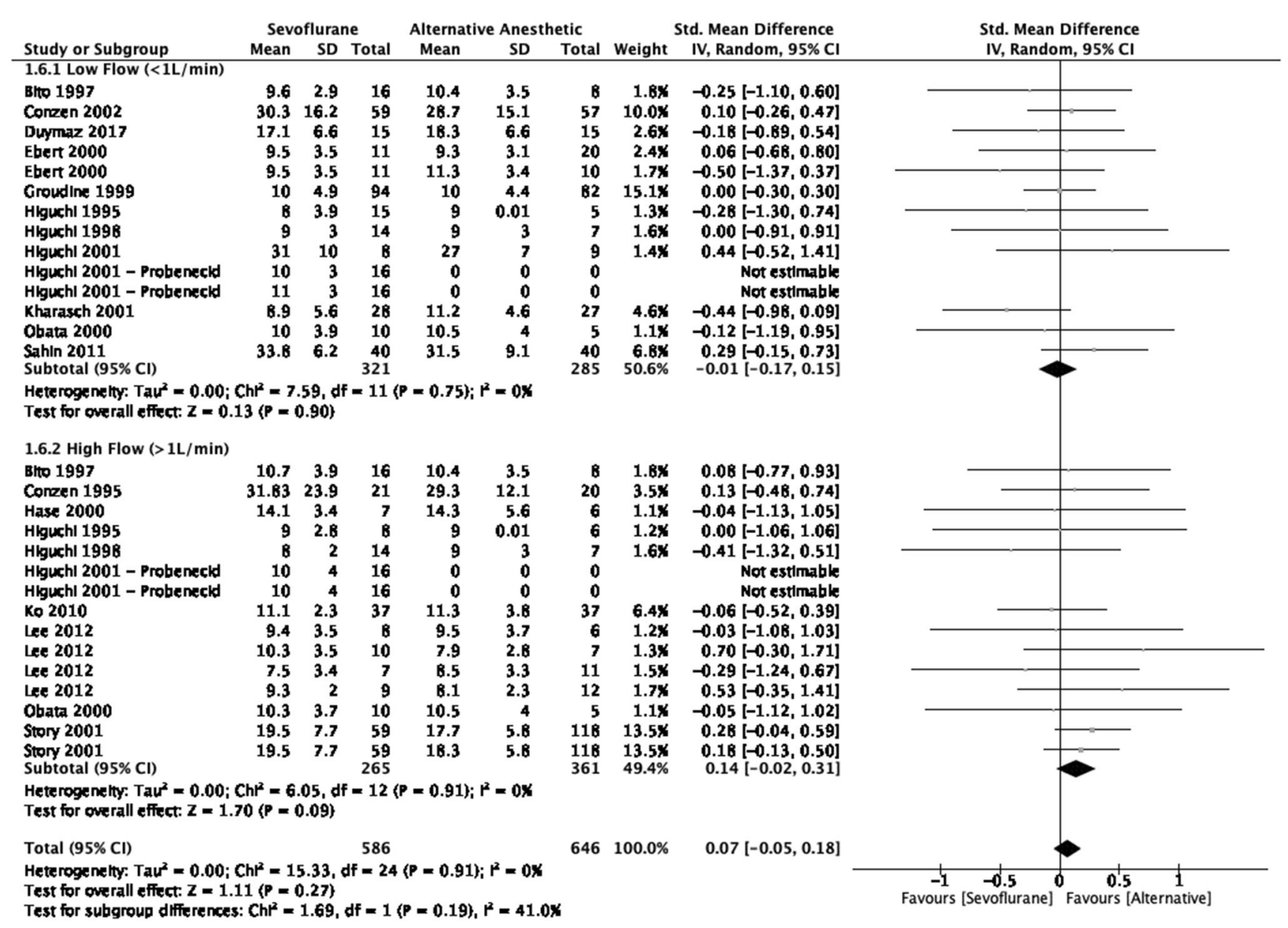

Fig. 12 Subgroup analysis showing the effect of sevoflurane $v s$ an alternate anesthetic agent on blood urea nitrogen (BUN) measured at 24 postoperative hours when delivered at low fresh-gas flow $(\leq 1 \mathrm{~L} \mathrm{FGF})$ or high fresh-gas flow ( $>1 \mathrm{~L}$ FGF)

nephrotoxicity. Also of concern have been factors like FGF, in particular LFA, pre-existing renal impairment, duration of sevoflurane anesthesia, and the choice of absorbent.

Prior renal dysfunction may be concerning to anesthesiologists if sevoflurane was to impact renal function. Our review identified a total of three studies ( $n$ $=174$ ) that were conducted in patients with preoperative stable renal dysfunction ${ }^{46,67,69}$ and two studies that were conducted in patients who had been exposed to nephrotoxic agents $^{33,44}$ None of these studies showed any significant impairment in RFT results following sevoflurane use compared with alternative anesthetics.
A second concern with the use of sevoflurane is its interaction with $\mathrm{CO}_{2}$ absorbents, which has driven the increased FGF recommendations by the manufacturers. Sevoflurane is known to interact with alkali-containing $(\mathrm{KOH}$ or $\mathrm{NaOH}) \mathrm{CO}_{2}$ absorbents such as soda lime or baralyme, resulting in alkaline degeneration and the subsequent formation of $\mathrm{CpdA}$. The effects of $\mathrm{CpdA}$ on subsequent renal dysfunction were brought into focus by animal studies and one trial in healthy volunteers from one group of researchers. ${ }^{72,76,77}$ This subsequently prompted public health departments worldwide to recommend a minimum FGF to diminish the accumulation of $\mathrm{CpdA}$ in the breathing circuits and consequently in the patients. 


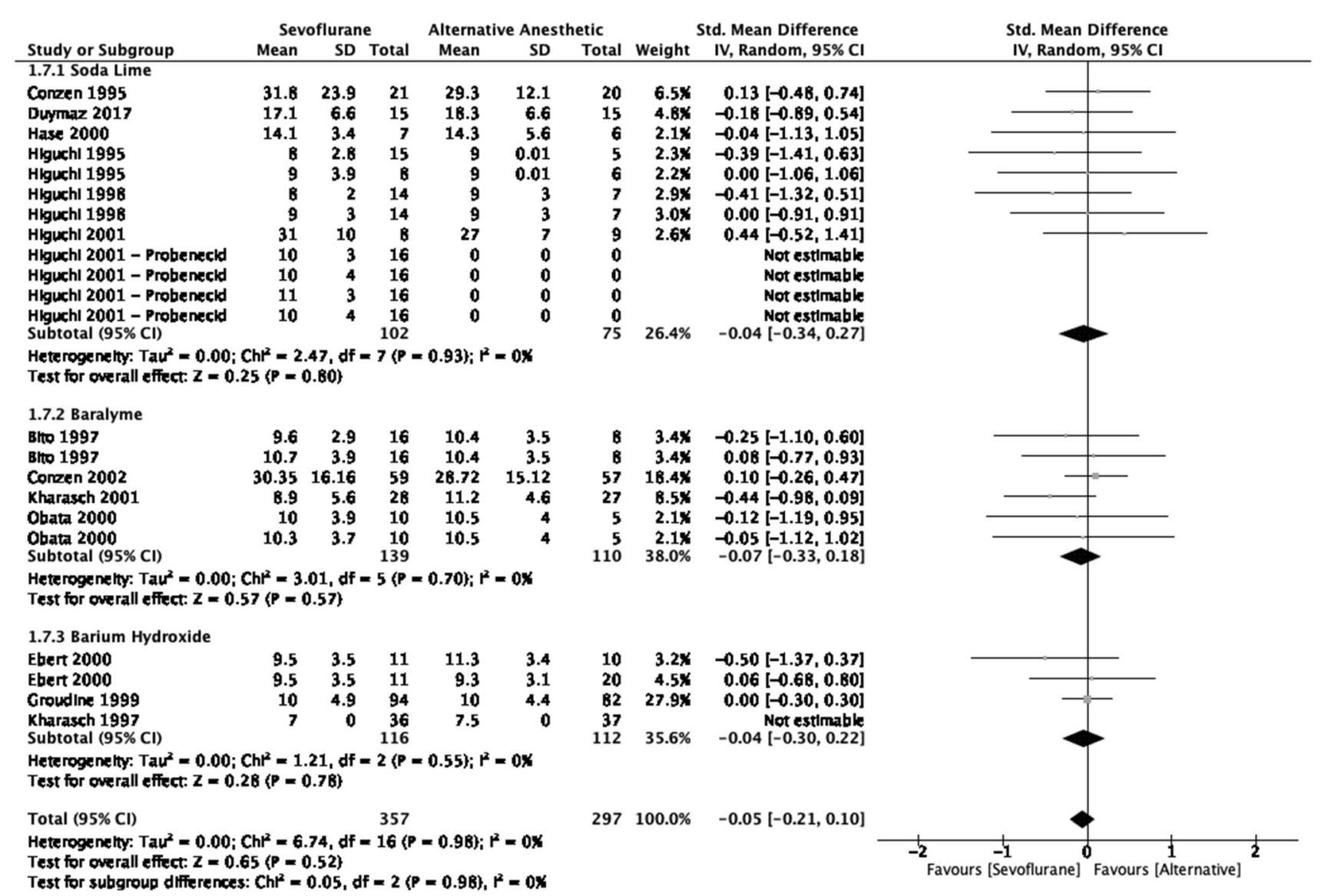

Fig. 13 Subgroup analysis showing the effect of sevoflurane $v s$ an alternate anesthetic agent on the blood urea nitrogen (BUN) measured at 24 postoperative hours when used in conjunction with various absorbents

Nevertheless, a lack of nephrotoxicity despite higher levels of exposure to $\mathrm{CpdA}$ has been shown in clinical studies. $^{45,50,78,79}$ The generation of $\mathrm{CpdA}$ and its subsequent accumulation may be related to a variety of factors such as the type and humidity of the absorbent, temperature, $\mathrm{CO}_{2}$ production, and FGFs. ${ }^{80,81}$ While $\mathrm{CpdA}$ exposure has shown to be cumulative with increasing duration of exposure in some studies, ${ }^{1,77,82}$ our metaregression plots with duration of anesthetic as the covariate did not find such an association, in agreement with other studies. $^{83,84}$

Peak plasma fluoride was elevated with sevoflurane use compared with the use of other halogenated agents such as isoflurane, desflurane, or enflurane. The mean pooled peak plasma fluoride after sevoflurane usage was 35.08 (95\% CI,
31.52 to 38.64), but some studies showed peak levels $>50$ $\mu \mathrm{M}^{42,43,48,49,58}$ The threshold for renal toxicity secondary to methoxyflurane anesthesia was accepted to be a plasma fluoride level of $50 \mu \mathrm{M}^{2}$ An important distinction between methoxyflurane and sevoflurane based on experimental and clinical evidence is that methoxyflurane undergoes not only extensive metabolism (70\%) but also intra-renal metabolism, which could have contributed to nephrotoxicity. While methoxyflurane-associated nephrotoxicity ranged from transient derangements in RFT results (such as creatinine or BUN) to fulminant vasopressin-resistant high-output renal failure, our review did not note any derangements in RFT results or incidences of overt renal failure with the sevoflurane use compared with the use of alternative anesthetics. 


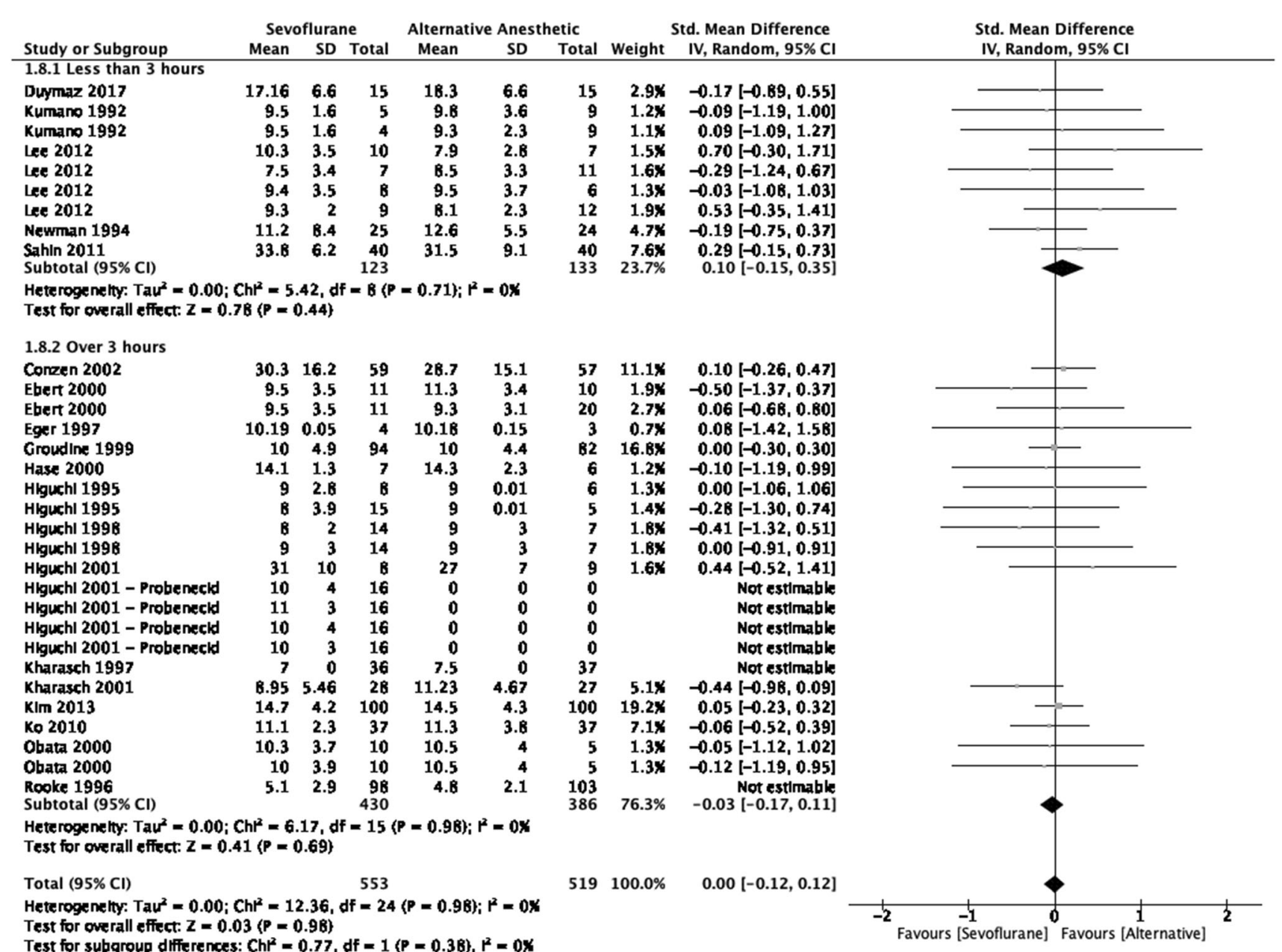

Fig. 14 Subgroup analysis showing the effect of sevoflurane $v s$ an alternate anesthetic agent on the blood urea nitrogen (BUN) measured at 24 postoperative hours when the duration of exposure is dichotomized to $\leq$ or $>$ three hours

Increasing FGF has been thought to reduce the risk of accumulating CpdA, which is based on in vitro studies showing a decreasing CpdA concentration with an increasing $\mathrm{FGF},{ }^{1}$ and this finding was reconfirmed in our meta-regression plots of CpdA and FGF. While increasing the FGF is thought to reduce the circuit concentrations of CpdA, whether such increases in FGF actually prevent CpdA-induced renal dysfunction has long been speculated. Our review identified 12 studies, including the ones with patients at risk for renal injury, ${ }^{33,44,46,69}$ that evaluated whether a low FGF sevoflurane anesthetic is injurious to kidneys. None of the studies showed any increase in BUN, $\mathrm{CCR}$, or creatinine following sevoflurane use compared with use of alternative anesthetics. ${ }^{33,37,42,43,45,50,62,63,69,71}$ A positive correlation has been suggested between the dosage of sevoflurane and the subsequent plasma fluoride levels ${ }^{85}$ but our meta-regression plots failed to note an association between increasing FGF or duration of exposure with subsequent plasma inorganic fluoride levels. This could be due to the saturable kinetics of sevoflurane metabolism, but further studies are needed to explore this. The fluoride load depends on the hepatic 


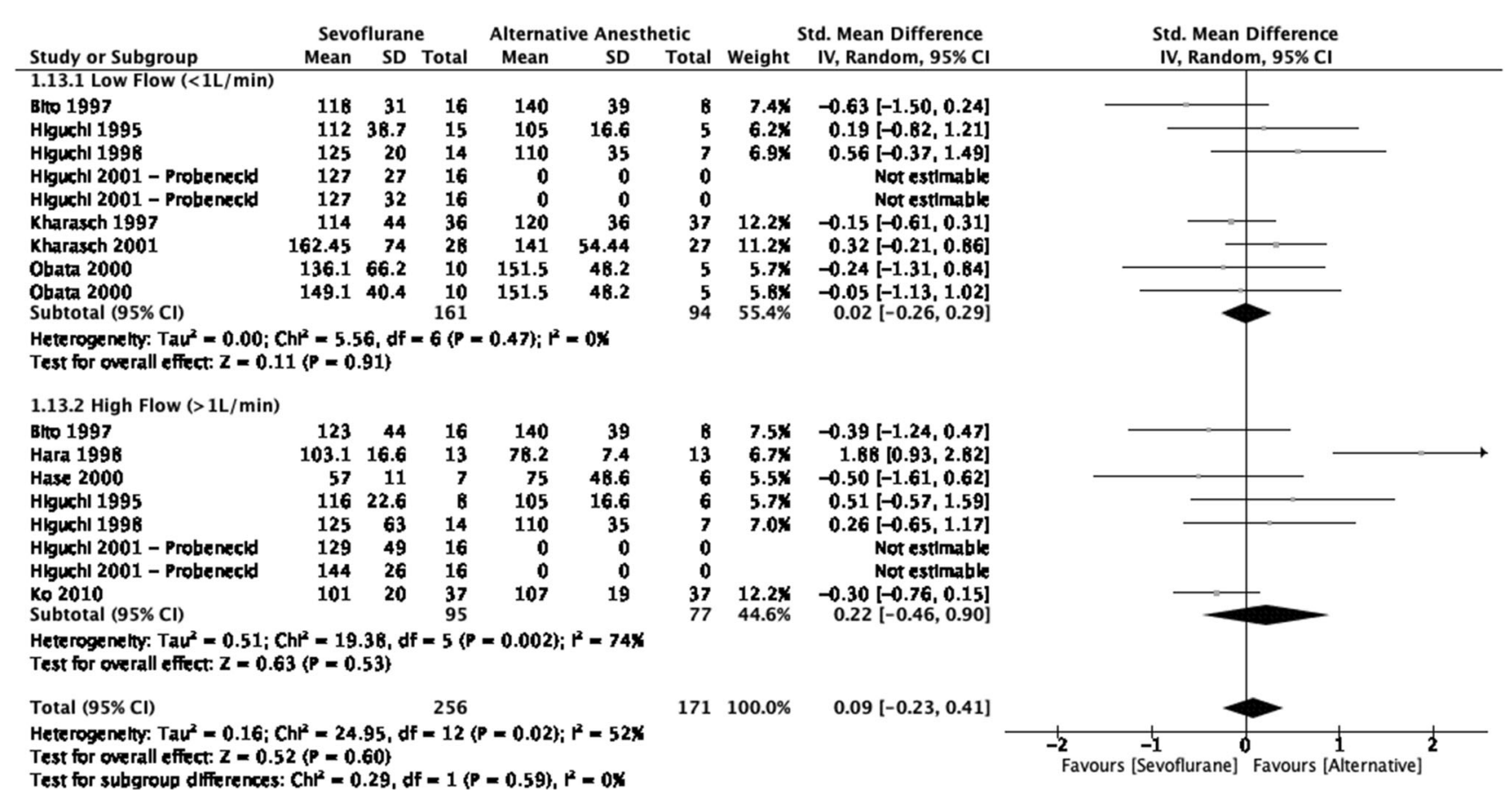

Fig. 15 Subgroup analysis showing the effect of sevoflurane $v s$ an alternate anesthetic agent on creatinine clearance (CCR) measured at 24 postoperative hours when delivered at low fresh-gas flow ( $\leq 1 \mathrm{~L}[\mathrm{FGF}])$ or high fresh-gas flow ( $>1 \mathrm{~L}$ FGF)

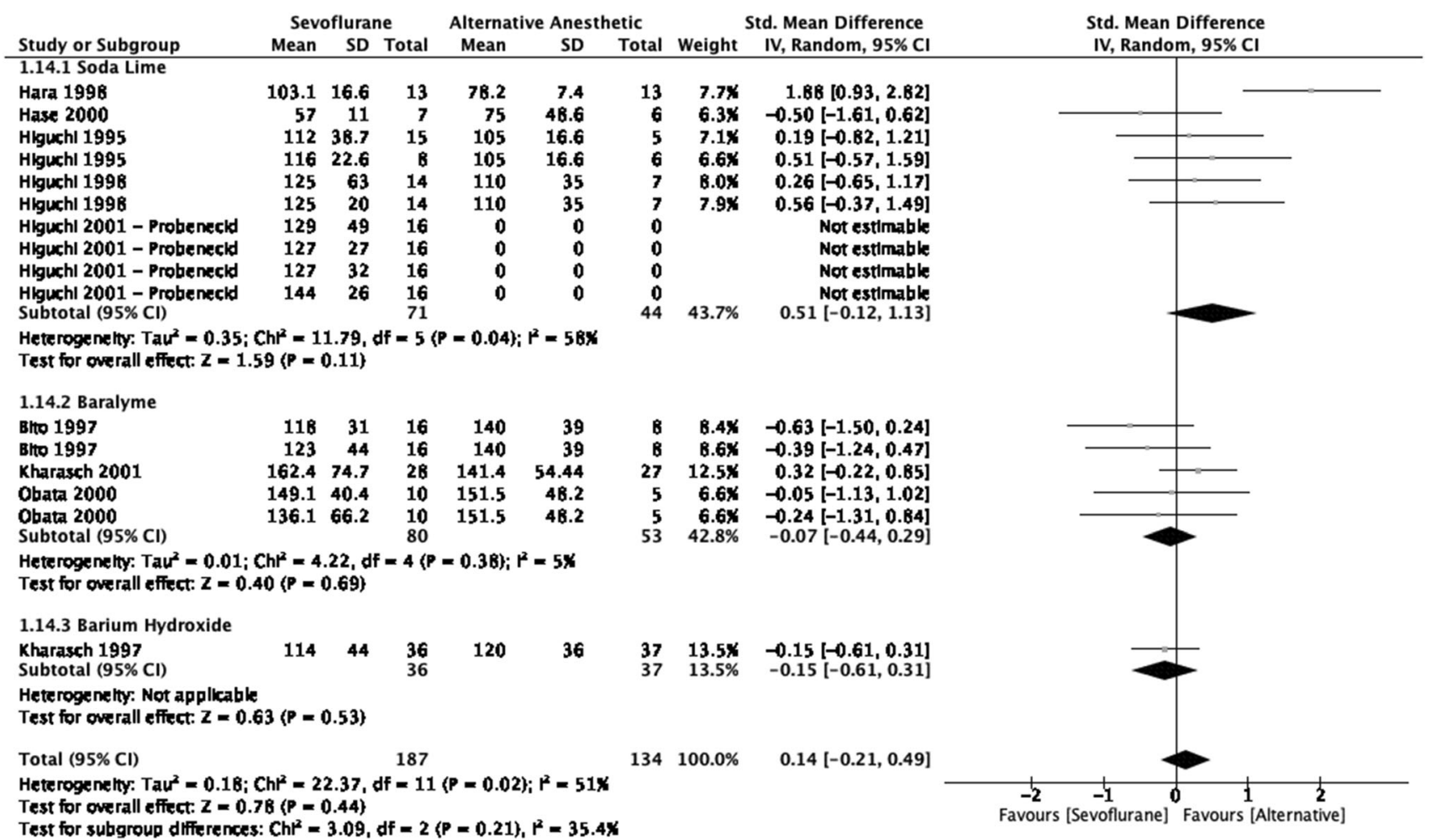

Fig. 16 Subgroup analysis showing the effect of sevoflurane $v s$ an alternate anesthetic agent on the creatinine clearance (CCR) measured at 24 postoperative hours when used in conjunction with various absorbents 


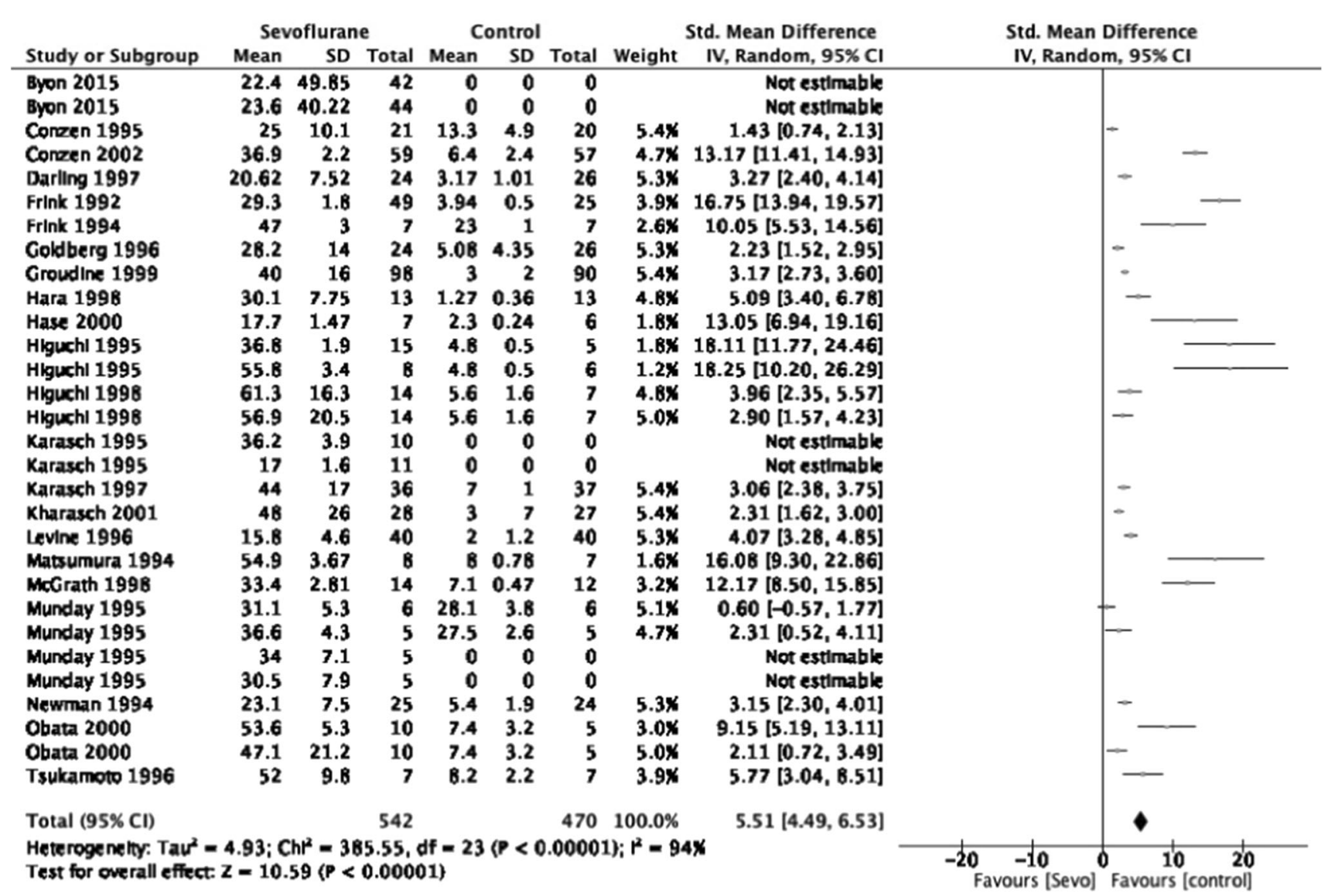

Fig. 17 Forest plot showing pooled estimate of peak plasma fluoride level for sevoflurane $v s$ an alternative inhaled anesthetic agent

metabolism of sevoflurane, which is much higher than that of other currently used halogenated agents and hence is independent of the sevoflurane load on the body in terms of FGF.

The rationale and the evidence for the lack of association between CpdA and nephrotoxicity in humans has been known for quite some time. ${ }^{85}$ There is a species difference in the occurrence of CpdA-mediated nephrotoxicity and is directly related to the ß-lyase activity of the tubular cells. A high activity of this enzyme is specific to rodents. Since non-rodents do not have a high $\beta$-lyase activity, the nephrotoxicity of $\mathrm{CpdA}$ is not significant as evidenced by animal and human studies on prolonged exposure to CpdA. A minimum FGF recommendation in product monographs to curb $\mathrm{CpdA}$ levels is unnecessary. With the introduction of newer alkali-free non-reactive absorbents such as litholyme and amsorb, minimally reactive absorbents containing soda lime, and with the end of the production of baralyme, the issue of $\mathrm{CpdA}$ generation is antiquated in current practice. $^{86,87}$

Based on the outcome of this meta-analysis, we conclude that sevoflurane does not contribute more to nephrotoxicity in humans than alternative anesthetics do. Often mistaken to generally be about nephrotoxicity or other organ toxicity, FGF recommendations for sevoflurane 
Table 2 Tubular function

\begin{tabular}{|c|c|c|c|}
\hline Tubular function & Studies (units of measurements) & Sevoflurane [mean (SD)] & Control [mean (SD)] \\
\hline \multirow[t]{4}{*}{ U-NAG $24 \mathrm{hr}$} & $\operatorname{Ammar} 2016^{34}\left(\mathrm{U} \cdot \mathrm{L}^{-1}\right)$ & $2.6(0.9)$ & $2.5(0.8)$ \\
\hline & Frink $1994^{73}\left(\mathrm{nmol} \cdot \mathrm{hr}^{-1} \cdot \mathrm{mg}^{-1} \mathrm{Cr}\right)$ & $45.0(16.67)$ & $30.0(8.33)$ \\
\hline & Matsumura $1994^{58}\left(\mathrm{U} \cdot \mathrm{hr}^{-1}\right)$ & $0.92(0.31)$ & $1.23(0.31)$ \\
\hline & Tsukamoto $1996^{65}\left(\mathrm{IU} \cdot \mathrm{day}^{-1}\right)$ & $28.57(14.29)$ & $42.86(21.43)$ \\
\hline \multirow[t]{8}{*}{ Cystatin-C $24 \mathrm{hr}$} & Duymaz $2017^{70}\left(\mathrm{mg} \cdot \mathrm{L}^{-1}\right)$ & $0.75(0.17)$ & $0.79(0.19)$ \\
\hline & Kumano $1992^{53}\left(\mathrm{mg} \cdot \mathrm{g}^{-1} \mathrm{Cr}\right)$ & $3.67(0.19)$ & $3.71(0.32) \& 3.58(0.2)$ \\
\hline & Wujtewicz $2012^{33}$ & $1044.45(821)$ & - \\
\hline & Chemo+LFA $\left(\mathrm{ng} \cdot \mathrm{mL}^{-1}\right)$ & & \\
\hline & Wujtewicz $2012^{33}$ & $1054.51(922.83)$ & - \\
\hline & Chemo+HFA $\left(\mathrm{ng} \cdot \mathrm{mL}^{-1}\right)$ & & \\
\hline & Wujtewicz $2012^{33}$ & $840.1(871.9)$ & - \\
\hline & No-chemo + LFA $\left(\mathrm{ng} \cdot \mathrm{mL}^{-1}\right)$ & & \\
\hline \multirow[t]{7}{*}{ U-Albumin } & Higuchi $2001^{46}$ Low flow + probenecid $\left(\mathrm{mg} \cdot 24 \mathrm{hr}^{-1}\right)$ & $12(7)$ & - \\
\hline & Higuchi $2001^{46}$ Low flow $\left(\mathrm{mg} \cdot 24 \mathrm{hr}^{-1}\right.$ ) & $55(87)$ & - \\
\hline & Higuchi $2001^{46}$ High flow + probenecid $\left(\mathrm{mg} \cdot 24 \mathrm{hr}^{-1}\right)$ & $15(12)$ & - \\
\hline & Higuchi $2001^{46}$ High flow $\left(\mathrm{mg} \cdot 24 \mathrm{hr}^{-1}\right.$ ) & $20(24)$ & - \\
\hline & Obata $2000^{62}$ Low flow $\left(\mathrm{mg} \cdot \mathrm{day}^{-1}\right)$ & $28.3(17.8)$ & $28.5(16.0)$ \\
\hline & Obata $2000^{62}$ High flow $\left(\mathrm{mg} \cdot \mathrm{day}^{-1}\right)$ & $41.5(29.0)$ & $28.5(16.0)$ \\
\hline & Conzen $2002^{69}\left(\mathrm{mg} \cdot 24 \mathrm{hr}^{-1}\right)$ & $974.0(1825.0)$ & $1076.0(1545.0)$ \\
\hline \multirow[t]{9}{*}{ U-Protein } & Higuchi $2001^{46}$ Low flow + probenecid $\left(\mathrm{mg} \cdot 24 \mathrm{hr}^{-1}\right)$ & $94(32)$ & \\
\hline & Higuchi $2001^{46}$ Low flow $\left(\mathrm{mg} \cdot 24 \mathrm{hr}^{-1}\right.$ ) & $279(508)$ & \\
\hline & Higuchi $2001^{46}$ High flow + probenecid $\left(\mathrm{mg} \cdot 24 \mathrm{hr}^{-1}\right)$ & $73(31)$ & \\
\hline & Higuchi $2001^{46}$ High flow $\left(\mathrm{mg} \cdot 24 \mathrm{hr}^{-1}\right)$ & $144(222)$ & \\
\hline & Obata $2000^{62}$ Low flow $\left(\mathrm{mg} \cdot 24 \mathrm{hr}^{-1}\right)$ & $300.0(135.0)$ & $311.0(220.0)$ \\
\hline & Obata $2000^{62}$ High flow $\left(\mathrm{mg} \cdot 24 \mathrm{hr}^{-1}\right)$ & $388.0(156.0)$ & $311.0(220.0)$ \\
\hline & Sahin $2011^{63}\left(\mathrm{mg} \cdot 24 \mathrm{hr}^{-1}\right)$ & $122.5(84.3)$ & $105.3(35.3)$ \\
\hline & Higuchi $1998^{43}$ & Recorded in log scale- not accurate & \\
\hline & Ammar $2016^{34}\left(\mathrm{mg} \cdot \mathrm{L}^{-1}\right)$ & $5.3(1.8)$ & $4.9(1.5)$ \\
\hline \multirow[t]{4}{*}{ U- å1 microglobulin } & Hase $2000^{40}\left(\mathrm{mg} \cdot \mathrm{g}^{-1} \mathrm{Cr}\right)$ & $19(3.8)$ & $22(7.6)$ \\
\hline & Matsumura $1994^{58}\left(\mathrm{mg} \cdot \mathrm{hr}^{-1}\right)$ & $3.9(0.48)$ & $2.18(0.29)$ \\
\hline & Kumano $1992^{53}\left(\mu \mathrm{g} \cdot \mathrm{g}^{-1} \mathrm{Cr}\right)$ & $1.36(0.57)$ & $1.14(0.25) \&$ \\
\hline & & & $1.03(0.18)$ \\
\hline \multirow[t]{8}{*}{ U $\beta$ microglobulin } & Higuchi $2001^{46}$ Low flow + probenecid $\left(\mathrm{mg} \cdot 24 \mathrm{hr}^{-1}\right)$ & $146(234.0)$ & \\
\hline & Higuchi $2001^{46}$ Low flow $\left(\mathrm{mg} \cdot 24 \mathrm{hr}^{-1}\right.$ ) & $3073(10294)$ & \\
\hline & Higuchi $2001^{46}$ high flow + probenecid $\left(\mathrm{mg} \cdot 24 \mathrm{hr}^{-1}\right)$ & $118(115)$ & \\
\hline & Higuchi $2001^{46}$ high flow $\left(\mathrm{mg} \cdot 24 \mathrm{hr}^{-1}\right)$ & $443(1317)$ & \\
\hline & Matsumura $1994^{58}\left(\mu \mathrm{g} \cdot \mathrm{hr}^{-1}\right)$ & $300.0(90)$ & $527.27(55)$ \\
\hline & Tsukamoto $1996^{65}\left(\mathrm{mg} \cdot \mathrm{day}^{-1}\right)$ & $25.0(12.0)$ & $9.0(2.0)$ \\
\hline & Higuchi $1998^{43}\left(\mu \mathrm{g} \cdot \mathrm{g}^{-1} \mathrm{Cr}\right)$ & $358(513) \& 159(141)$ & $174.78(178)$ \\
\hline & Ammar $2016^{34}\left(\mu \mathrm{g} \cdot \mathrm{L}^{-1}\right)$ & $15.5(4.9)$ & $13.5(5.4)$ \\
\hline \multirow[t]{2}{*}{$\pi$-GST } & Kharasch $1997^{50}\left(\mathrm{ng} \cdot \mathrm{mg}^{-1} \mathrm{Cr}\right)$ & $30.0(20.0)$ & $23.0(20.0)$ \\
\hline & Conzen $1995^{67}\left(\mathrm{mOsm} \cdot \mathrm{kg}^{-1}\right)$ & $489.0(29.0)$ & $445.0(31.0)$ \\
\hline \multirow[t]{4}{*}{ Urine osmolality } & Darling $1997^{68}\left(\mathrm{mOsm} \cdot \mathrm{kg}^{-1}\right)$ & $377(210)$ & $461(279)$ \\
\hline & Frink $1994^{73}\left(\mathrm{mOsm} \cdot \mathrm{kg}^{-1}\right)$ & $1077.55(44.44)$ & $857.14(88.88)$ \\
\hline & Newman $1994^{61}\left(\mathrm{mmol} \cdot \mathrm{kg}^{-1}\right)$ & $485(49)$ & $541(46)$ \\
\hline & Bito $1997^{45}$ Low flow $\left(\mathrm{U} \cdot \mathrm{g}^{-1} \mathrm{Cr}\right)$ & $4.6(4.1)$ & $5.9(3.7)$ \\
\hline
\end{tabular}


Table 2 continued

\begin{tabular}{|c|c|c|c|}
\hline Tubular function & Studies (units of measurements) & Sevoflurane [mean (SD)] & Control [mean (SD)] \\
\hline \multirow[t]{20}{*}{$\mathrm{AG} / \mathrm{Cr} 24 \mathrm{hr}$} & Bito $1997^{45}$ High flow $\left(\mathrm{U} \cdot \mathrm{g}^{-1} \mathrm{Cr}\right.$ ) & $7.8(7.8)$ & $5.9(3.7)$ \\
\hline & Hara $1998^{39}$ & $9.4(1.04)$ & $7.3(1.74)$ \\
\hline & Hase $2000^{40}$ & $17.8(2.38)$ & $21.16(2.44)$ \\
\hline & Higuchi $2001^{46}$ Low flow + probenecid $\left(\mathrm{mg} \cdot 24 \mathrm{hr}^{-1}\right)$ & $1.6(1.1)$ & \\
\hline & Higuchi $2001^{46}$ Low flow $\left(\mathrm{mg} \cdot 24 \mathrm{hr}^{-1}\right)$ & $2.9(4.9)$ & \\
\hline & Higuchi $2001^{46}$ High flow + probenecid $\left(\mathrm{mg} \cdot 24 \mathrm{hr}^{-1}\right)$ & $2.2(0.9)$ & \\
\hline & Higuchi $2001^{46}$ High flow (mg.24 $\mathrm{hr}^{-1}$ ) & $2.6(1.3)$ & \\
\hline & Higuchi $1995^{42}$ Low fluoride $\left(\mathrm{U} \cdot \mathrm{g}^{-1} \mathrm{Cr}\right.$ ) & $1.7(0.2)$ & $1.7(0.3)$ \\
\hline & Higuchi $1995^{42}$ High fluoride $\left(\mathrm{U} \cdot \mathrm{g}^{-1} \mathrm{Cr}\right.$ ) & $2.2(0.5)$ & $1.7(0.3)$ \\
\hline & Higuchi $1998^{43}$ Low flow (U.g ${ }^{-1} \mathrm{Cr}$ ) & $2.2(1.41)$ & $2.0(0.57)$ \\
\hline & Higuchi $1998^{43}$ High flow $\left(\mathrm{U} \cdot \mathrm{g}^{-1} \mathrm{Cr}\right)$ & $1.8(0.71)$ & $2.0(0.57)$ \\
\hline & Kharasch $1997^{50}\left(\mathrm{mU} \cdot \mathrm{mg}^{-1} \mathrm{Cr}\right)$ & $4.2(0.6)$ & $6(2.5)$ \\
\hline & Kumano $1992^{53}\left(\mathrm{U} \cdot \mathrm{g}^{-1} \mathrm{Cr}\right)$ & $24.21(37.89)$ & $6.32(6.32) \& 4.21(5.26)$ \\
\hline & Lee $2012^{54}$ & $6.4(5.5)$ & $5.6(2.7)$ \\
\hline & Sodasorblime (IU.g $\left.\mathrm{g}^{-1} \mathrm{Cr}\right)$ & & \\
\hline & Lee $2012^{54}$ Sodalyme $\left(\mathrm{IU} \cdot \mathrm{g}^{-1} \mathrm{Cr}\right)$ & $5.6(1.3)$ & $7.6(4.8)$ \\
\hline & $\begin{array}{l}\text { Lee } 2012^{54} \text { Sodasorb- } \\
\left(\mathrm{IU} \cdot \mathrm{g}^{-1} \mathrm{Cr}\right)\end{array}$ & $4.3(3.3)$ & $7.4(2.7)$ \\
\hline & Lee $2012^{54}$ Spherasorb- (IU.g ${ }^{-1} \mathrm{Cr}$ ) & $7.5(4.6)$ & $5.2(3.0)$ \\
\hline & Obata $2000^{62}$ Low flow $\left(\mathrm{U} \cdot \mathrm{g}^{-1} \mathrm{Cr}\right.$ ) & $15.2(14.8)$ & $15.0(7.9)$ \\
\hline & Obata $2000^{62}$ High flow (U.g ${ }^{-1} \mathrm{Cr}$ ) & $15.5(10.2)$ & $15.0(7.9)$ \\
\hline
\end{tabular}

$\mathrm{Cr}=$ creatinine; $\mathrm{SD}=$ standard deviation

are only tied to CpdA production. While many European countries eliminated FGF recommendations for sevoflurane in the late 1990s, other countries and healthcare systems still have FGF recommendations in place today. This has significantly increased wasteful spending on anesthetic agents but more importantly, has increased the atmospheric release of a very potent greenhouse gas. ${ }^{6}$ It is very hard to change a product monograph and there is no financial benefit for drug manufacturers to apply to regulatory bodies to do so. More important will be for anesthesia societies to issue practice advisories based on available evidence, incorporating the availability of non-reactive absorbents, and to refute existing FGF recommendations for sevoflurane. This is a patient safety issue in that there is a false sense of unsafe practice when a physician runs a low FGF sevoflurane anesthetic. Practice advisories will also reduce fear of litigation.

\section{Limitations}

There are certain limitations to our review. Our review did not identify studies with exposure beyond eight hours, so 
Table 3 Summary of evidence

\begin{tabular}{|c|c|c|c|}
\hline Nephrotoxicity of sevoflurane compa & nesthetics & & \\
\hline $\begin{array}{l}\text { Intervention: Sevoflurane } \\
\text { Comparison: Alternative anesthetics }\end{array}$ & & & \\
\hline \multirow[t]{2}{*}{ Outcomes } & \multirow[t]{2}{*}{$\begin{array}{l}\text { № of participants } \\
\text { (studies) } \\
\text { Follow-up }\end{array}$} & \multirow[t]{2}{*}{$\begin{array}{l}\text { Certainty of the } \\
\text { evidence } \\
\text { (GRADE) }\end{array}$} & $\begin{array}{c}\text { Anticipated absolute } \\
\text { effects }\end{array}$ \\
\hline & & & $\begin{array}{l}\text { Risk difference with } \\
\text { Sevoflurane }\end{array}$ \\
\hline Creatinine $24 \mathrm{hr}$ & $\begin{array}{c}1949 \\
(24 \mathrm{RCTs})\end{array}$ & $\begin{array}{l}\oplus \oplus{ }_{\mathrm{LOW}}^{\mathrm{a}, \mathrm{b}} \\
\end{array}$ & $\begin{array}{l}\text { SMD 0.04 SD higher } \\
\text { ( } 0.06 \text { lower to } 0.13 \text { higher })\end{array}$ \\
\hline CCR $24 \mathrm{hr}$ & $\begin{array}{c}728 \\
(12 \mathrm{RCTs})\end{array}$ & $\begin{array}{c}\oplus \oplus \oplus \bigcirc \\
\text { MODERATE }^{a}\end{array}$ & $\begin{array}{c}\text { SMD 0.14 SD higher } \\
\text { (0.09 lower to } 0.37 \text { higher })\end{array}$ \\
\hline BUN $24 \mathrm{hr}$ & $\begin{array}{c}1529 \\
(21 \mathrm{RCTs})\end{array}$ & $\begin{array}{l}\oplus \oplus{ }^{\mathrm{a}} \\
\mathrm{LOW}^{\mathrm{a}, \mathrm{b}}\end{array}$ & $\begin{array}{l}\text { SMD 0.06 SD higher } \\
(0.04 \text { lower to } 0.16 \text { higher })\end{array}$ \\
\hline Fluoride $24 \mathrm{hr}$ & $\begin{array}{c}651 \\
(15 \mathrm{RCTs})\end{array}$ & $\begin{array}{l}\oplus \oplus \oplus \oplus \\
\mathrm{HIGH}^{\mathrm{a}}\end{array}$ & $\begin{array}{c}\text { MD } 6.16 \text { higher } \\
\text { (4.42 higher to } 7.9 \text { higher) }\end{array}$ \\
\hline Peak serum fluoride & $\begin{array}{c}1012 \\
(20 \mathrm{RCTs})\end{array}$ & $\begin{array}{l}\oplus \oplus \oplus \oplus \\
\text { HIGH }^{\mathrm{a}}\end{array}$ & $\begin{array}{c}\text { SMD 5.51 SD higher } \\
\text { (4.49 higher to } 6.53 \\
\text { higher) }\end{array}$ \\
\hline
\end{tabular}

$\mathrm{BUN}=$ blood urea nitrogen $\mathrm{CCR}=$ creatinine clearance $\mathrm{CI}=$ Confidence interval $; \mathrm{RCT}=$ randomized-controlled trial $; \mathrm{SMD}=$ standardized mean difference

\section{GRADE Working Group grades of evidence}

High certainty: We are very confident that the true effect lies close to that of the estimate of the effect

Moderate certainty: We are moderately confident in the effect estimate: The true effect is likely to be close to the estimate of the effect, but there is a possibility that it is substantially different

Low certainty: Our confidence in the effect estimate is limited: The true effect may be substantially different from the estimate of the effect Very low certainty: We have very little confidence in the effect estimate: The true effect is likely to be substantially different from the estimate of effect

\section{Explanations}

a. The risk of bias assessment had quite a few studies with unclear risk of bias

b. The SMD varied highly between the trials

the long-term safety of sevoflurane may need further study. We also cannot comment on the safety of sevoflurane on other organ systems as this was beyond the purview of our review. We did not look at the effect of hepatic enzyme induction as seen in patients with alcohol abuse, or intake of certain medications (barbiturates, phenytoin), and we excluded certain vulnerable patient populations such as patients with cirrhosis and patients undergoing organ transplant in whom the metabolism of sevoflurane may be altered; further studies are needed to investigate these factors. The tubular function tests conducted across various studies were inconsistent in the timepoints of reporting and the units of measurement. Future studies should focus on utilizing consistent units of measurement when reporting these outcome measures for better comparability.

Our rating of the study quality was low to medium, as most studies had problems with physician- and allocation blinding. Conducting studies while ensuring blinding of the performer can be difficult when utilizing inhaled anesthetic agents and would not have affected the laboratory measurements used in this analysis. Because of the inherent difficulty in blinding the anesthesiologist to which vapor is being used, it is also unlikely that blinded studies (i.e., with low risk of bias) can be conducted in the future or that these would yield different outcome measurements. 
We extrapolated median $(\mathrm{CI} / \mathrm{IQR} / \mathrm{SE})$ values into mean (SD) values for many data points of included studies using approved meta-analytical methods. These extrapolated values can vary depending on how the conversions were made, and a different method of estimation may have potentially affected our conclusions. Future studies performed in low FGF settings with different newer absorbents may affect our conclusions and more studies or population-based safety data are needed to definitively conclude our findings. Although we performed a thorough search, there is a possibility of missed studies. In addition, we could not retrieve the full text of six studies despite multiple attempts.

\section{Conclusions}

Based on the data extracted from 41 RCTs, sevoflurane usage did not increase renal dysfunction compared with other agents used for anesthesia maintenance. This was true when sevoflurane was administered with low FGF, in patients with stable renal dysfunction, with different absorbents, and at varying duration of exposure. Sevoflurane results in higher fluoride load and accumulation of CpdA with no adverse effects on renal function. While the formation of inorganic fluoride had no relationship to FGF or duration of exposure, the formation of CpdA showed an inverse relationship to FGF. Minimum FGF recommendations for sevoflurane anesthesia are not supported by our analysis and should be reconsidered.

\begin{abstract}
Author contributions Rakesh Sondekoppam and Timur Özelsel contributed to all aspects of this manuscript, including study conception and design; acquisition, analysis, and interpretation of data; and drafting the article. Karim Narsingani and Trent Schimmel contributed to the acquisition and analysis of data. Brie McConnell contributed to the acquisition and analysis of data and to the drafting of the manuscript. Karen Buro contributed to the analysis and interpretation of data and to drafting of the manuscript.
\end{abstract}

Acknowledgements Shiori Matsuda, Kaho Hosoi, and Hitoki Mizumuta from Meiji Pharmaceutical university Tokyo. Dr. GyuJeong Noh for providing the data. Kurt Weckesser University of Alberta. Dr. Jan-Peter Jantzen for help with the final manuscript.

Contributor and guarantor information The corresponding author attests that all listed authors meet authorship criteria and that no others meeting the criteria have been omitted.

Disclosures All authors have completed the Unified Competing Interest form (available on request from the corresponding author) and declare no support from any organization for the submitted work; no financial relationships with any organizations that might have an interest in the submitted work in the previous three years; and no other relationships or activities that could appear to have influenced the submitted work. Part of this work was accepted for and presented at the annual meeting of the American Society of Anesthesiology (19-23 October 2019; Orlando, FL).
Funding statement This study was not funded externally. All time and resources were provided by the study team.

Editorial responsibility This submission was handled by Dr. Hilary P. Grocott, Editor-in-Chief, Canadian Journal of Anesthesia. The authors consent to sharing the raw data of the study and to linking it to a published article.

\section{References}

1. Abbvie Ltd. ULTANE® (sevoflurane) volatile liquid for inhalation. Available from URL: https://www.accessdata.fda. gov/drugsatfda_docs/label/2017/020478s030lbl.pdf (accessed June 2020).

2. Mazze RI. Methoxyflurane revisited: tale of an anesthetic from cradle to grave. Anesthesiology 2006; 105: 843-6.

3. Gentz, BA, Malan TP Jr. Renal toxicity with sevoflurane: a storm in a teacup? Drugs 2001; 61: 2155-62.

4. Alexander R, Poznikoff A, Malherbe S. Greenhouse gases: the choice of volatile anesthetic does matter. Can J Anesth 2018; 65: 221-2.

5. Hanna $M$, Bryson $G L$. A long way to go: minimizing the carbon footprint from anesthetic gases. Can J Anesth 2019; 66: 838-9.

6. Ozelsel TJ, Sondekoppam RV, Buro K. The future is now-it's time to rethink the application of the global warming potential to anesthesia. Can J Anesth 2019; 66: 1291-5.

7. République Française; Ministère des solidarités et de la santé. Base de données publique des médicaments. Résumé des caractéristiques du produit - SEVORANE, liquide pour inhalation par vapeur. Available from URL: http://basedonnees-publique.medicaments.gouv.fr/affichageDoc. php?specid $=66282739 \&$ typedoc $=\mathrm{R}$ (accessed June 2020).

8. AbvVie Ltd. Sevoflurane Inhalation Vapour, Liquid - Summary of Product Characteristics (SmPC) - (emc). Available from URL: https://www.medicines.org.uk/emc/product/833 (accessed June 2020).

9. Baxter. Sevofluran Baxter. Fachinformation. Available from URL: https://www.baxter.de/sites/g/files/ebysai1301/files/201901/sevofluran_baxter_fs.pdf (accessed June 2020).

10. Ong Sio LC, Dela Cruz RG, Bautista AF. Sevoflurane and renal function: a meta-analysis of randomized trials. Med Gas Res 2017; DOI: https://doi.org/10.4103/2045-9912.215748.

11. Higgins JP, Green S. Cochrane Handbook for Systematic Reviews of Interventions Version 5.1.0 [updated March 2011]. Available from URL: https://training.cochrane.org/handbook/ archive/v5.1/ (accessed May 2020).

12. Moher D, Liberati A, Tetzlaff J, Altman DG; PRISMA Groupl. Preferred reporting items for systematic reviews and metaanalyses: the PRISMA statement. PLoS Med 2009; DOI: https:// doi.org/10.1371/journal.pmed.1000097.

13. Wan $X$, Wang W, Liu J, Tong T. Estimating the sample mean and standard deviation from the sample size, median, range and/or interquartile range. BMC Med Res Methodol 2014; DOI: https:// doi.org/10.1186/1471-2288-14-135.

14. Cohen J. Statistical Power Analysis for the Behavioral Sciences. 2nd ed. NY: Lawrence Erlbaum Associates; 1988.

15. El Refai N, Mandour E. Effect of low-flow sevoflurane anaesthesia combined with epidural block on stress response, hepatic and renal functions in patients undergoing total abdominal hysterectomy. Egypt J Anaesth 2003; 19: 155-61.

16. Abdel-Latif MM, Elgammal SA. Serum fluoride ion and renal function after prolonged sevoflurane or isoflurane anaesthesia. Egypt J Anaesth 2003; 19: 79-83. 
17. Al-Sayed GG, Soliman AH. Hepatic and renal glomerulotubular effects of sevoflurane versus isoflurane in prolonged anaesthesia. Egypt J Anaesth 2003; 19: 149-54.

18. Iskender A, Altan A, Ozyuvaci E, Ertugrul OO. The effects of desflurane and sevoflurane anesthesia on renal function (Turkish). Anestezi Dergisi 2004; 12: 253-8.

19. Ohira $N$, Inada $T$, Hamai $R$. Influence of sevoflurane and isoflurane anesthesia on renal function in elderly patients (Japanese). Masui 1994; 43: 1842-5.

20. Ranieri $R$, Martinelli $G$, Pagani I, et al. Maintenance and recovery characteristics of sevoflurane anaesthesia in adult patients. A multicenter, randomized comparison with isoflurane. Minerva Anestesiol 1998; 64: 11-7.

21. Yoon HK, Oh H, Lee HC, et al. Effect of sevoflurane postconditioning on the incidence of symptomatic cerebral hyperperfusion after revascularization surgery in adult patients with Moyamoya disease. World Neurosurg 2020; 134: e9911000.

22. Li H, Weng Y, Yuan S, Liu W, Yu H, YuW. Effect of sevoflurane and propofol on acute kidney injury in pediatric living donor liver transplantation. Ann Transl Med 2019; DOI: http://dx.doi.org/10. 21037/atm.2019.06.76.

23. Ong Sio LC, Dela Cruz RG, Bautista AF. A comparison of renal responses to sevoflurane and isoflurane in patients undergoing donor nephrectomy: a randomized controlled trial. Med Gas Res 2017; DOI: https://doi.org/10.4103/2045-9912.202906.

24. Rooke GA, Ebert T, Muzi M, Kharasch ED. The hemodynamic and renal effects of sevoflurane and isoflurane in patients with coronary artery disease and chronic hypertension. Sevoflurane Ischemia Study Group. Anesth Analg 1996; 82: 1159-65.

25. Savran Karadeniz M, Senturk Ciftci H, Tefik T, et al. Effects of different volatile anesthetics on cytokine and chemokine production after ischemia-reperfusion injury in patients undergoing living-donor kidney transplant. Exp Clin Transplant 2019; 17(Suppl 1): 68-74.

26. Abou Hussein M, Mahmoud F, Beltagy R, Hasanin A, Yassen K, Attar A. Desflurane compared to sevoflurane for cirrhotic patients undergoing major liver resection. a randomized control study. Middle East J Anaesthesiol 2015; 23: 213-23.

27. Song JC, Zhang MZ, Wu QC, et al. Sevoflurane has no adverse effects on renal function in cirrhotic patients: a comparison with propofol. Acta Anaesthesiol Scand 2013; 57: 896-902.

28. Nieuwenhuijs-Moeke GJ, Nieuwenhuijs VB, Seelen MA, et al. Propofol-based anaesthesia versus sevoflurane-based anaesthesia for living donor kidney transplantation: results of the VAPOR-1 randomized controlled trial. Br J Anaesth 2017; 118: 720-32.

29. Laisalmi M, Teppo AM, Koivusalo AM, Honkanen E, Valta P, Lindgren $L$. The effect of ketorolac and sevoflurane anesthesia on renal glomerular and tubular function. Anesth Analg 2001; 93: 1210-3.

30. Julier $K$, da Silva $R$, Garcia $C$, et al. Preconditioning by sevoflurane decreases biochemical markers for myocardial and renal dysfunction in coronary artery bypass graft surgery: a double-blinded, placebo-controlled, multicenter study. Anesthesiology 2003; 98: 1315-27.

31. Higuchi H, Adachi Y, Arimura S, Kanno M, Satoh T. Compound A concentrations during low-flow sevoflurane anesthesia correlate directly with the concentration of monovalent bases in carbon dioxide absorbents. Anesth Analg 2000; 91: 434-9.

32. Igarashi $M$, Watanabe $H$, Iwasaki $H$, Namiki A. Clinical evaluation of low-flow sevoflurane anaesthesia for paediatric patients. Acta Anaesthesiol Scand 1999; 43: 19-23.

33. Wujtewicz M, Sawicka W, Wenski W, et al. The influence of lowflow anaesthesia on renal function in cancer patients previously treated with nephrotoxic chemotherapeutic agents. Anaesthesiol Intensive Ther 2012; 44: 71-5.
34. Ammar AS, Mahmoud KM. Comparative effect of propofol versus sevoflurane on renal ischemia/reperfusion injury after elective open abdominal aortic aneurysm repair. Saudi J Anaesth 2016; 10: 301-7.

35. Frink EJ Jr, Ghantous H, Malan TP, et al. Plasma inorganic fluoride with sevoflurane anesthesia: correlation with indices of hepatic and renal function. Anesth Analg 1992; 74: 231-5.

36. Goldberg ME, Cantillo J, Larijani GE, Torjman M, Vekeman D, Schieren $H$. Sevoflurane versus isoflurane for maintenance of anesthesia: are serum inorganic fluoride ion concentrations of concern? Anesth Analg 1996; 82: 1268-72.

37. Groudine SB, Fragen RJ, Kharasch ED, Eisenman TS, Frink EJ, McConnell S. Comparison of renal function following anesthesia with low-flow sevoflurane and isoflurane. J Clin Anesth 1999; 11: 201-7.

38. Hamimy W, Ashour E, Afify M. Effect of regional epidural ropivacaine anesthesia on $\alpha$ glutathione-S-transferase: comparison with low-flow sevoflurane and total intravenous propofol anesthesia. J Biol Sci 2004; 4: 398-404.

39. Hara T, Fukusaki M, Nakamura T, Sumikawa $K$. Renal function in patients during and after hypotensive anesthesia with sevoflurane. J Clin Anesth 1998; 10: 539-45.

40. Hase $K$, Meguro K, Nakamura T. Effects of sevoflurane anesthesia combined with epidural block on renal function in the elderly: comparison with isoflurane. J Anesth 2000; 14: 5360.

41. Hatano M, Asada A, Nishi S, et al. Maternal and fetal serum inorganic fluoride levels following isoflurane and sevoflurane anesthesia for cesarean section [Japanese]. Hiroshima J Anesth 1993; 29: 49-51.

42. Higuchi $H$, Sumikura $H$, Sumita $S$, et al. Renal function in patients with high serum fluoride concentrations after prolonged sevoflurane anesthesia. Anesthesiology 1995; 83: 449-58.

43. Higuchi H, Sumita S, Wada H, et al. Effects of sevoflurane and isoflurane on renal function and on possible markers of nephrotoxicity. Anesthesiology 1998; 89: 307-22.

44. Higuchi $H$, Adachi $Y$. Renal function in surgical patients after administration of low-flow sevoflurane and amikacin. J Anesth 2002; 16: 17-22.

45. Bito H, Ikeuchi $Y$, Ikeda K. Effects of low-flow sevoflurane anesthesia on renal function: comparison with high-flow sevoflurane anesthesia and low-flow isoflurane anesthesia. Anesthesiology 1997; 86: 1231-7.

46. Higuchi H, Adachi $Y$, Wada H, Kanno M, Satoh T. The effects of low-flow sevoflurane and isoflurane anesthesia on renal function in patients with stable moderate renal insufficiency. Anesth Analg 2001; 92: 650-5

47. Higuchi H, Wada H, Usui Y, Goto K, Kanno M, Satoh T. Effects of probenecid on renal function in surgical patients anesthetized with low-flow sevoflurane. Anesthesiology 2001; 94: 21-31.

48. Kharasch ED, Armstrong AS, Gunn K, Artru A, Cox K, Karol $M D$. Clinical sevoflurane metabolism and disposition. II. The role of cytochrome P450 2E1 in fluoride and hexafluoroisopropanol formation. Anesthesiology 1995; 82: 1379-88.

49. Kharasch ED, Frink EJ Jr, Artru A, Michalowski P, Rooke GA, Nogami $W$. Long-duration low-flow sevoflurane and isoflurane effects on postoperative renal and hepatic function. Anesth Analg 2001; 3: 1511-20.

50. Kharasch ED, Frink EJ Jr, Zager R, Bowdle TA, Artru A, Nogami $W M$. Assessment of low-flow sevoflurane and isoflurane effects on renal function using sensitive markers of tubular toxicity. Anesthesiology 1997; 86: 1238-53.

51. Kim JW, Kim JD, Yu SB, Ryu SJ. Comparison of hepatic and renal function between inhalation anesthesia with sevoflurane and remifentanil and total intravenous anesthesia with propofol and 
remifentanil for thyroidectomy. Korean J Anesthesiol 2013; 64: 112-6.

52. Ko JS, Gwak MS, Choi SJ, et al. The effects of desflurane and sevoflurane on hepatic and renal functions after right hepatectomy in living donors. Transpl Int 2010; 23: 736-44.

53. Kumano $H$, Osaka S, Ishimura N, Nishiwada M. Effects of enflurane, isoflurane, and sevoflurane on renal tubular functions (Japanese). Masui 1992; 41: 1735-40.

54. Lee HC, Kim D, Ahn W, Sim J, Chung Y. Comparison of the renal safety between carbon dioxide absorbent products under sevoflurane anesthesia: a pilot study. Korean J Anesthesiol 2012; 63: 11-7.

55. Levine MF, Sarner J, Lerman J, et al. Plasma inorganic fluoride concentrations after sevoflurane anesthesia in children. Anesthesiology 1996; 84: 348-53.

56. Byon HJ, Choi BM, Bang JY, et al. An open-label comparison of a new generic sevoflurane formulation with original sevoflurane in patients scheduled for elective surgery under general anesthesia. Clin Ther 2015; 37: 887-901.

57. Lorsomradee S, Cromheecke S, Lorsomradee S, De Hert SG. Effects of sevoflurane on biomechanical markers of hepatic and renal dysfunction after coronary artery surgery. J Cardiothorac Vasc Anesth 2006; 20: 684-90.

58. Matsumura C, Kemmotsu O, Kawano Y, Takita K, Sugimoto H, Mayumi T. Serum and urine inorganic fluoride levels following prolonged low-dose sevoflurane anesthesia combined with epidural block. J Clin Anesth 1994; 6: 419-24.

59. McGrath BJ, Hodgins LR, DeBree A, Frink EJ Jr, Nossaman BD, Bikhazi GB. A multicenter study evaluating the effects of sevoflurane on renal function in patients with renal insufficiency. J Cardiovasc Pharmacol Ther 1998; 3: 229-34.

60. Munday IT, Stoddart PA, Jones RM, Lytle J, Cross MR. Serum fluoride concentration and urine osmolality after enflurane and sevoflurane anesthesia in male volunteers. Anesth Analg 1995; 81: 353-9.

61. Newman PJ, Quinn AC, Hall GM, Grounds RM. Circulating fluoride changes and hepatorenal function following sevoflurane anaesthesia. Anaesthesia 1994; 49: 936-9.

62. Obata R, Bito H, Ohmura M, et al. The effects of prolonged lowflow sevoflurane anesthesia on renal and hepatic function. Anesth Analg 2000; 91: 1262-8.

63. Sahin SH, Cinar SO, Paksoy I, Sut N, Oba S. Comparison between low-flow sevoflurane anesthesia and total intravenous anesthesia during intermediate-duration surgery: effects on renal and hepatic toxicity. Hippokratia 2001; 15: 69-74.

64. Story DA, Poustie S, Liu G, McNicol PL. Changes in plasma creatinine concentration after cardiac anesthesia with isoflurane, propofol, or sevoflurane: a randomized clinical trial. Anesthesiology 2001; 95: 842-8.

65. Tsukamoto N, Hirabayashi $Y$, Shimizu R, Mitsuhata $H$. The effects of sevoflurane and isoflurane anesthesia on renal tubular function in patients with moderately impaired renal function. Anesth Analg 1996; 82: 909-13.

66. Wiesner G, Wild K, Schwurzer S, Merz M, Hobbhahn J. Serum fluoride concentrations and exocrine kidney function with sevoflurane and enflurane. An open, randomized, comparative phase III study of patients with healthy kidneys (German). Anaesthesist 1996; 45: 31-6.

67. Conzen PF, Nuscheler M, Melotte A, et al. Renal function and serum fluoride concentrations in patients with stable renal insufficiency after anesthesia with sevoflurane or enflurane. Anesth Analg 1995; 81: 569-75.

68. Darling JR, Murray JM, McBride DR, Trinick TR, Fee JP. Serum glutathione S-transferase concentrations and creatinine clearance after sevoflurane anaesthesia. Anaesthesia 1997; 52: 121-6.
69. Conzen PF, Kharasch ED, Czerner SF, et al. Low-flow sevoflurane compared with low-flow isoflurane anesthesia in patients with stable renal insufficiency. Anesthesiology 2002; 97: 578-84.

70. Duymaz G, Yagar S, Ozgok A. Comparison of effects of low-flow sevoflurane and low-flow desflurane anaesthesia on renal functions using cystatin C. Turkish J Anaesthesiol Reanim 2017; 45: 93-7.

71. Ebert TJ, Arain SR. Renal responses to low-flow desflurane, sevoflurane, and propofol in patients. Anesthesiology 2000; 93: 1401-6.

72. Eger EI 2nd, Koblin DD, Bowland T, et al. Nephrotoxicity of sevoflurane versus desflurane anesthesia in volunteers. Anesth Analg 1997; 84: 160-8.

73. Frink EJ Jr, Malan TP Jr, Isner RJ, Brown EA, Morgan SE, Brown BR. Renal concentrating function with prolonged sevoflurane or enflurane anesthesia in volunteers. Anesthesiology 1994; 80: 1019-25.

74. Brown B Jr. Sevoflurane: introduction and overview. Anesth Analg 1995; 81(5Suppl) S1-3.

75. Brioni JD, Varughese $S$, Ahmed R, Bein B. A clinical review of inhalation anesthesia with sevoflurane: from early research to emerging topics. J Anesth 2017; 31: 764-78.

76. Eger EI 2nd, Gong D, Koblin DD, et al. Dose-related biochemical markers of renal injury after sevoflurane versus desflurane anesthesia in volunteers. Anesth Analg 1997; 85: 1154-63.

77. Eger EI 2nd, Ionescu P, Laster MJ, Gong D, Weiskopf RB, Kerschmann RL. Quantitative differences in the production and toxicity of $\mathrm{CF} 2=\mathrm{BrCl}$ versus $\mathrm{CH} 2 \mathrm{~F}-\mathrm{O}-\mathrm{C}(=\mathrm{CF} 2)(\mathrm{CF} 3)$ (compound $\mathrm{A}$ ): the safety of halothane does not indicate the safety of sevoflurane. Anesth Analg 1997; 85: 1164-70.

78. Bito H, Ikeda K. Renal and hepatic function in surgical patients after low-flow sevoflurane or isoflurane anesthesia. Anesth Analg 1996; 82: 173-6.

79. Mazze RI, Callan CM, Galvez ST, Delgado-Herrera L, Mayer $D B$. The effects of sevoflurane on serum creatinine and blood urea nitrogen concentrations: a retrospective, twenty-two-center, comparative evaluation of renal function in adult surgical patients. Anesth Analg 2000; 90: 683-8.

80. Fang ZX, Eger EI 2nd. Factors affecting the concentration of compound A resulting from the degradation of sevoflurane by soda lime and baralyme in a standard anesthetic circuit. Anesth Analg 1995; 81: 564-8.

81. Fang ZX, Kandel L, Laster MJ, Ionescu P, Eger EI. Factors affecting production of compound A from the interaction of sevoflurane with baralyme and soda lime. Anesth Analg 1996; 82: 775-81.

82. Eger EI 2nd, Gong D, Koblin DD, et al. The effect of anesthetic duration on kinetic and recovery characteristics of desflurane versus sevoflurane, and on the kinetic characteristics of compound A, in volunteers. Anesth Analg 1998; 86: 414-21.

83. Bito $H$, Ikeda $K$. Effect of total flow rate on the concentration of degradation products generated by reaction between sevoflurane and soda lime. Br J Anaesth 1995; 74: 667-9.

84. Bito H, Ikeda $K$. Long-duration, low-flow sevoflurane anesthesia using two carbon dioxide absorbents. Quantification of degradation products in the circuit. Anesthesiology 1994; 81: 340-5.

85. Reichle FM, Conzen PF, Peter K. Nephrotoxicity of halogenated inhalational anaesthetics: fictions and facts. Eur Surg Res 2002; 34: $188-95$

86. Marini F, Bellugi I, Gambi D, et al. Compound A, formaldehyde and methanol concentrations during low-flow sevoflurane anaesthesia: comparison of three carbon dioxide absorbers. Acta Anaesthesiol Scand 2007; 51: 625-32. 
87. Epstein RH, Maguire DP, Dexter F. Reduction in sevoflurane FGF following introduction of a lithium-based $\mathrm{CO} 2$ absorbent. Anesth Analg 2015; 120: S369 (abstract).
Publisher's Note Springer Nature remains neutral with regard to jurisdictional claims in published maps and institutional affiliations. 